\title{
New species of the ground sloth Parocnus from the late Pleistocene-early Holocene of Hispaniola
}

\section{Robert K. McAfee 1 , Sophia M. Beery ${ }^{2}$, Renato Rimoli ${ }^{3}$, Juan Almonte ${ }^{4}$, Phillip Lehman ${ }^{5}$, and Siobhán B. Cooke ${ }^{6}$}

${ }^{1}$ Department of Biomedical Sciences, Philadelphia College of Osteopathic Medicine - Georgia, Suwanee, GA, USA, rkmcafee@gmail.com;

2Department of Biological Sciences, Ohio University, Athens, OH, USA, drbeercat@gmail.com;

${ }^{3}$ Museo del Hombre Dominicano, Plaza de la Cultura, Santo Domingo, D.N., Republica Dominicana, rimoli28@hotmail.com;

${ }^{4}$ Museo Nacional de Historia Natural "Prof. Eugenio de Jesús Marcano," Santo Domingo, D.N., Republica Dominicana,

j.almonte@mnhn.gov.do;

${ }^{5}$ Dominican Republic Speleological Society, Republica Dominicana, philliplehman@mac.com;

${ }^{6}$ Center for Functional Morphology and Evolution, Johns Hopkins University School of Medicine, Baltimore, MD, USA, scooke5@jhmi.edu

Abstract: Parocnus dominicanus sp. nov. represents a new species of megalonychid ground sloth from the Altagracia Province of southeastern Dominican Republic. Specimens of multiple individuals, including one associated partial skeleton, were recovered from two separate underwater caves in the Parque Nacional del Este through collaborations with museums and cave divers between 2009-2013. Parocnus dominicanus sp. nov. is distinguished by its small size compared to that of $P$. serus, with percent differences in limb element lengths ranging from $13-24 \%$. Numerous cranial and post-cranial elements also exhibit morphological character states that are not attributable to size variations. The recovery of multiple individuals within each locality demonstrates a size dimorphism, possibly sexual, which parallels patterns exhibited by $P$. serus. The two species are also geographically distinct, with no examples of co-occurrence at any localities to date. Parocnus dominicanus sp. nov. and $P$. serus share character states that are distinct from those of the Cuban species, $P$. browni, and which suggest differential usage of the forelimb. The exact age of the specimens described here is unknown, however, Parocnus has been dated to the Holocene in Haiti.

http://zoobank.org/urn:lsid:zoobank.org:pub:12E495D3-E261-4522-9854-D3B4C2D5FFB8

\section{INTRODUCTION}

Parocnus (Miller 1929) is currently known from Holocene deposits from two of the Greater Antilles islands, Cuba and Hispaniola (Steadman et al. 2005). The history of this genus is complex; various elements now attributed to Parocnus have previously been assigned to a number of different genera and species. Initial descriptions of some Cuban specimens used the name Mesocnus (Matthew 1931), which is now mostly viewed as a junior synonym (see White and MacPhee 2001). Some Parocnus elements have been attributed to Neocnus comes (Paula Couto 1967;
White and MacPhee 2001). Parocnus has also been considered to be a generic junior of Megalocnus (Miller 1922; Mathew and Paula Couto 1959). In 2001, White and McPhee established the validity and priority of Parocnus in the context of describing new fossil sloth material from Haiti but noted that because of a scarcity of specimens and unexplored intraspecific variation patterns for Cuban Parocnus, some specimens could still be valid as a unique and separate genus, e.g., Mesocnus. Regardless, the presently accepted taxonomy recognizes just two species of Parocnus: P. browni (Matthew 1931) of Cuba and P. serus (Miller 1929) of Hispaniola. 
McAfee et al. - New species of the ground sloth Parocnus

Parocnus has, until recently, been poorly represented in paleontological sites and collections in Hispaniola, but new sloth material from caves in the Dominican Republic has provided sufficient samples to reassess the genus. As a result, recent research exploring the intraspecific variation of sloths from Hispaniola revealed the potential for the existence of two species of Parocnus on the island (McAfee and Beery 2017, 2021). That work provided quantitative and statistical data outlining two distinct size variants that could not be explained by sexual dimorphism or geographical variation, but stopped short of officially establishing a new species until qualitative morphological characters could be established. Having completed a more detailed comparison, here, we present the second and newest species of Parocnus from the island of Hispaniola.

\section{MATERIALS AND METHODS}

Specimens of Parocnus examined and included in this study are housed at the following institutions: American Museum of Natural History, New York, NY, USA (AMNH), Museo del Hombre Dominicano, Santo Domingo, Dominican Republic (MHD), Museo Nacional de Historia Natural, Santo Domingo, Dominican Republic (MNHN-SD), National Museum of Natural History, Washington DC, USA (NMNH), University of Florida, Vertebrate Paleontology Collections, Gainesville, FL, USA (UF-VP). Age class determination follows Naples (1982) and Anderson and Handley (2001). For the limb bones, age determination was related to the presence/absence of epiphyseal sutures. All individuals included in the study are considered to be adults unless otherwise noted. 3D files of type and paratype materials are available for viewing on Morphosource. Comparison photos of the holotype elements for P. serus are included to provide some comparison but newer specimens from $\mathrm{Ni}$ Rahu are not included in order to prevent conflict with a forthcoming revision of the species.

Abbreviations: C, cervical vertebra; Cf/cf, Upper/lower caniniform; Mc, metacarpal; Mf/mf, upper/lower molariform; mm, millimeters; Mt, metatarsal.

\section{SYSTEMATIC PALEONTOLOGY}

Class MAMMALIA Linnaeus, 1758

Order PILOSA Flower, 1883

Suborder FOLIVORA Delsuc et al., 2001

Family MEGALONYCHIDAE Gervais, 1855

Genus PAROCNUS Miller, 1929

Parocnus dominicanus sp. nov.

(Figs.1-17; 3D files on Morphosource)

Type species: Parocnus serus
Diagnosis: Distinguishable from the type specimens of Parocnus serus by the following characters: maximum humeral length $<170 \mathrm{~mm}$; proximal margins of tubercles unequal, lesser tubercle distal to the greater; humeral diaphysis slightly bowed and humeral head medially offset from longitudinal plane of the diaphysis; medial and lateral fossae of deltopectoral crest equal in size; maximum fibular length $<125 \mathrm{~mm}$; fibular head more inclined and indentation of medial margin occurs at anteroposterior midpoint; lateral malleolus with prominent posterior flange that bears a tuberosity and distinct tendon groove; calcaneal tendon flange on proximolateral side flattened and with two tendon grooves; calcaneal foramen distal to the lateral tendon flange is larger.

The following characters are also referred to the distinction of Parocnus dominicanus, based on comparison with nontype specimens of $P$. serus: elements (appendicular and axial) are shorter and narrower; union of temporal lines forming the sagittal crest occurs anterior to squamosal process roots; cf1 roots create a prominent bulge along the medioventral mandibular border; labial margins of $\mathrm{mf} 1$ and $\mathrm{mf} 2$ alveoli are unequal; dorsal and ventral arch tubercles of $\mathrm{C} 1$ absent or weak; anterior projection of occipital condyle facets for $\mathrm{C} 1$ minimal with respect to the ala and dorsal arch in dorsal view; caudal alar wing margins are minimally extended, slightly separated from axial/caudal articular facets, and caudal alar tubercles are medially positioned; caudal articular facets of $\mathrm{C} 2$ minimally extend caudally beyond the dorsal spinous process; caudal surface of $\mathrm{C} 2$ spinous process lacks a distinct depression at its base; odontoid process rounded and blunt; rib 1 sternal tubercle reduced, more caudally located, and further deflected away from the diaphysis; sternal end of rib 1 is narrow; maximum radial length $<130 \mathrm{~mm}$; radial head more ovate than circular and the proximal margins are mediolaterally even; maximum ulnar length $<170 \mathrm{~mm}$; tubercle between base of olecranon process and trochlear notch is absent; maximum radial length $<130 \mathrm{~mm}$; long axis of radial head oriented anteromedial to posterolateral; anterior and posterior radial head margins less angled and closer to horizontal; scaphoid facet along the styloid process uniformly wide and untapered; Mc3 maximum length $<33$ mm; Mc3 dorsal articular facet for Mc4 flat; Mc4 maximum length $<40 \mathrm{~mm}$; Mc4 articulation with Mc5 positioned palmarly and does not extend distally; maximum femoral length $<220 \mathrm{~mm}$; greater trochanter equal to femoral head height; maximum tibial length $<230 \mathrm{~mm}$; lateral tibial condyle posteriorly displaced from anterior margin and distolaterally sloped; tibial tuberosity more distal from tibial plateau and has a more prominent lateral protrusion; distal discoid and odontoid facets have a prominent separation; discoid facet more concave; distal fibular articular facet surface squared; Mt2 diaphysis mediolaterally constricted; Mt2 facet for Mt 1 
extends from dorsal to palmar margins; $\mathrm{Mt} 2$ carina obscured in lateral view; Mt 4 diaphysis narrow with sharp ridges and cuboid facet is rectilinear.

Etymology: Although never specified by Miller (1929), we hypothesize Parocnus to have meant "other sloth" [para- $($ Greek $)=$ other, besides; - ocnus $($ Greek $)=$ sloth], as a way to distinguish it from the other erected sloth taxa at the time, many of which utilized size-based names (e.g., Megalocnus, Microcnus). Para- has been used in a similar manner for the genus Paramylodon (Brown 1903), and -ocnus has been a common ending for sloth taxa within the Caribbean (although it has been used elsewhere as well (i.e., Thalassocnus)). The new species name is given to reflect and honor the Dominican Republic where the specimens have so far been found. Recommended common name: Dominican Parocnus.

Material: Holotype - MHD 237, partial skeleton collected on July 13, 2010 by Walter Pickle and Kurt Bowen. The recovered associated elements consist of the following: cranium with only the right Mf3, edentulous fragment of the posterior right mandible, five thoracic vertebrae, right and left rib 1, and various other rib fragments, right and left scapulae and humeri, nearly complete pelvis, right and left femora and tibiae, and a right fibula (Fig. 1).

Paratypes - A full list of specimens is given in Appendix 1. From the type locality of Padre Nuestro, the following specimens are referred: two partial mandibulae, two humeri (left and right), three ulnae (1 left and 2 right), partial pelvis, left femur, two left fibulae. Also referred to the paratype are the following specimens from La Jeringa: four partial crania, two atlas $(\mathrm{C} 1)$ vertebrae, two axis $(\mathrm{C} 2)$ vertebrae,

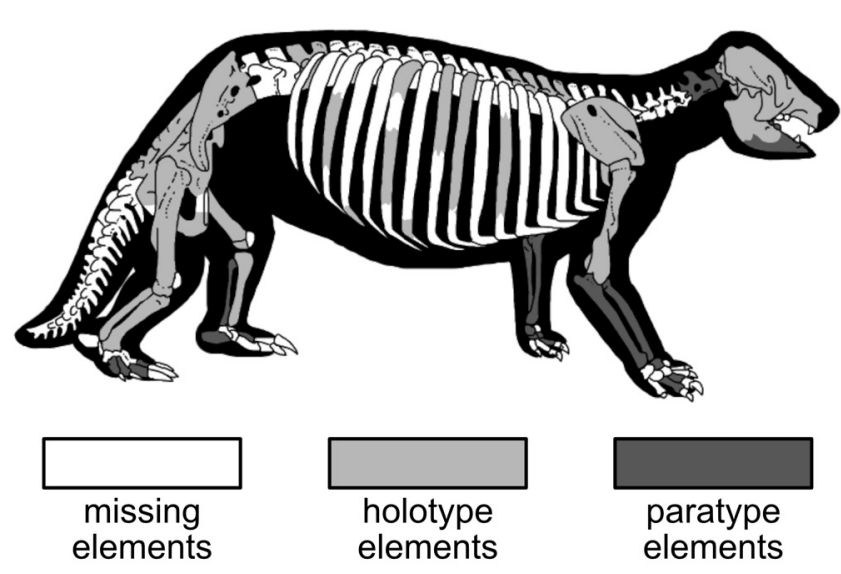

Figure 1. Bone map for Parocnus dominicanus indicating bones from the holotype (MHD 237) from Padre Nuestro and the paratype specimens from Padre Nuestro and La Jeringa. The skeletal model is based on known elements and previous reconstructions of Parocnus browni and Megalocnus rodens (Fischer 1971; Paula Couto 1956). Illustrative artwork by S. Beery partial right scapula, two radii (left and right), left ulna, two scaphoids (left and right), magnum (left), cuneiform (left), two Mc3s (left and right), two right Mc4s, left femur, two tibiae (left and right), left fibula, left calcaneus, right $\mathrm{Mt} 2$, and left Mt4.

Occurrence: Type locality is Padre Nuestro cave within the Nacional Parque del Este, Altagracia Province, Dominican Republic. Additional referred material is from the nearby cave $(<500 \mathrm{~m})$ of La Jeringa (Fig. 2).

Site description: Specimens of this species are confined to the southeastern Dominican Republic in and around Parque Nacional del Este in Altagracia Province (Fig. 2). The type locality, Padre Nuestro ("Our Father"), is a paleontologically-rich water-filled cave that has yielded several thousand mammalian fossils including rodents, eulipotyphlan insectivores, primates (Kay et al. 2011), bats, and two genera of sloths (Acratocnus and Parocnus). There are at least 5 individuals of Parocnus dominicanus (MNI: 5 right ulnae). The entrance to the cavern is $\sim 10 \mathrm{~m}$ deep and the system as a whole has a maximum depth of $12 \mathrm{~m}$; the majority of the fossils were recovered in the main cavern area. Although filled with fresh water today, travertine cave formations indicate that it was once dry.

A second locality, La Jeringa is located less than $1 \mathrm{~km}$ away in a now abandoned pumping station. The name translates to "the syringe," which is a reference to the pipe from the pumping station plunging down into the cave. Historically, water was drawn from the cave for the surrounding area. It is a smaller complex with many narrow passageways and no cave decorations, indicating that it was unlikely to have been dry in the past. It has a maximum depth of $15 \mathrm{~m}$. The site has fewer fossils overall, but is rich in sloth specimens. At least 12 individuals of Parocus dominicanus have been recovered (MNI: 12 right femora). Additionally, a juvenile primate is known from the site (Rosenberger et al. 2011, 2013), as are rodents.

Simplified maps of each locality can be viewed through the Dominican Republic Speleological Society (https:// www.dr-ss.com/la-jeringa and https://www.dr-ss.com/ padre-nuestro).

Geochronology: A detailed geochronological study of Padre Nuestro and La Jeringa has not be conducted; however, Padre Nuestro and the surrounding caves are found in a karst formation from Quaternary corals raised during the Pleistocene (Draper et al. 1994). There are many caves in the region, both filled with water and dry. A U-Pb date of 1.32 \pm 0.11 million years from speleothem encrusting an endemic primate (Antillothrix bernensis) tibia has been recovered from Padre Nuestro (Rosenberger et al. 2015) indicating that the cave has been open since at least that time. 


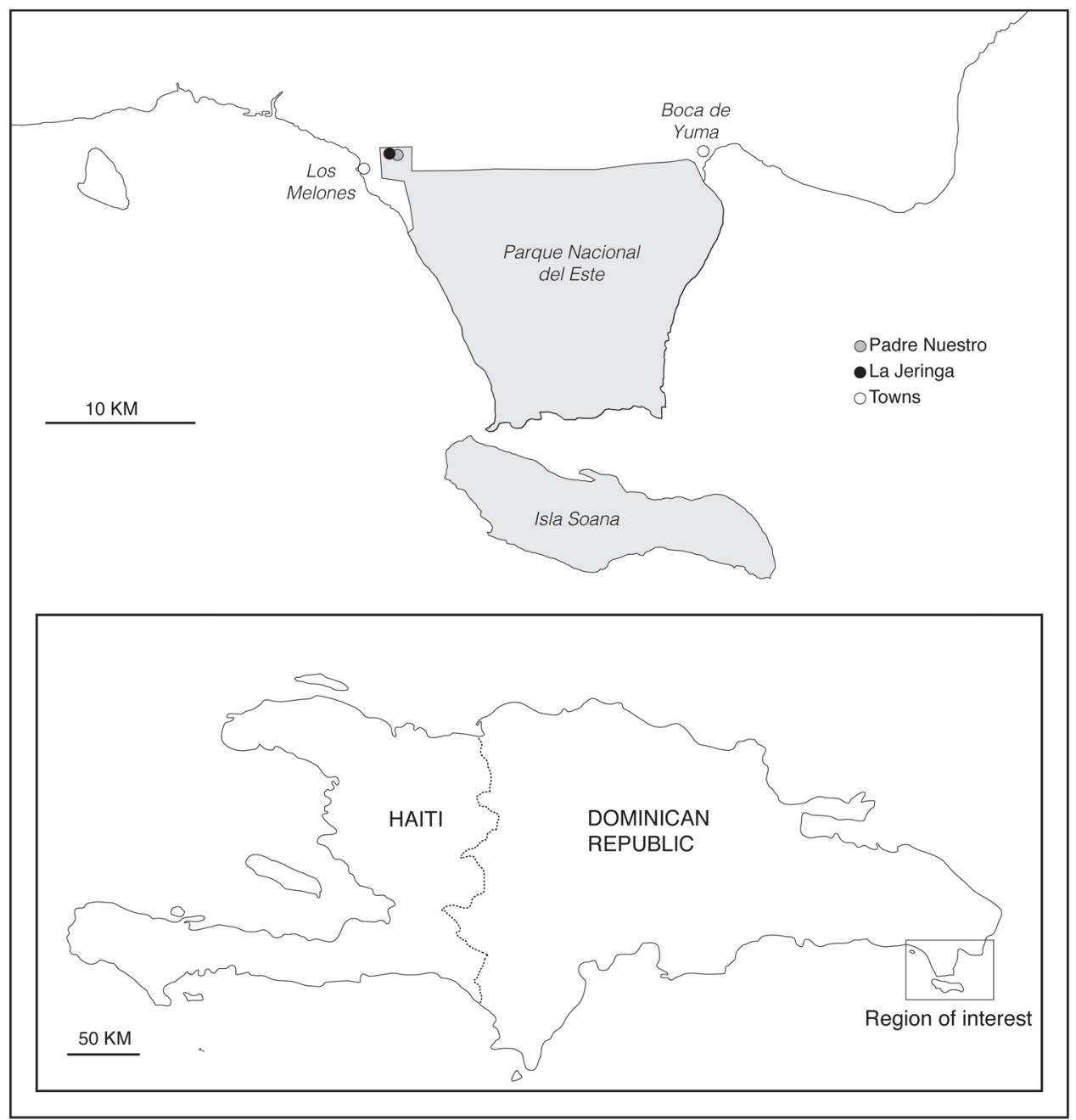

FIGURE 2. Map of Altagracia Province in southeastern Dominican Republic and the site localities in Nacional Parque del Este.

Attempts to recover collagen from specimens from Padre Nuestro have failed to produce any results, likely due to the long-submerged status of the elements. Radiocarbon dating undertaken in 2009 on four sloth humeri from La Jeringa was unsuccessful. Sloth specimens from several caves in Haiti (Steadman et al. 2005) have yielded Holocene dates. Cueva de Berna, a dry cave approximately $20 \mathrm{~km}$ east of Padre Nuestro (the type site for Antillothrix bernensis) has charcoal associated with faunal remains from which a radiocarbon date of $3850 \pm 150 \mathrm{yr}$ BP was obtained (Rímoli 1977). The fauna present in Padre Nuestro and La Jeringa is similar to that found in these dated sites, though, the Haitian sites do contain a much greater diversity of rodents from the genus Plagiodontia (Hansford et al. 2012).

\section{DESCRIPTION}

\section{Holotype - MHD 237}

Cranium: This specimen is edentulous (like all the assigned crania); portions of most of the alveolar walls are damaged, although the alveolae of the Mf1 and Mf2 are complete on both sides. There is also damage to the basal portions of the cranium and attaching pterygoids; both jugals are also absent. The individual is considered a full adult because there are no signs of cranial sutures remaining (age class 3 sensu Anderson and Handley 2001). Despite the incomplete condition of both this specimen and the paratypes, enough anatomy is preserved to allow comparison with the limited cranial material of $P$. serus. The crania of both species are similar in morphology and relative dimensions, but $P$. dominicanus is smaller than $P$. serus in most dimensions (Tab. 1).

In lateral views (Fig. 3B, C), the rostrum of the holotype is rather flat compared to that of the holotype for $P$. browni (AMNH 16877), in which the anterior portion of the frontals is quite bulged. This difference does not appear to be diagnostic because the paratype crania for $P$. dominicanus (see below, Fig. 11) also exhibit frontals bulged with respect to the nasals similar to that seen in P. browni. Variation in rostrum shape and/or doming of the cranium is common within Acratocnus, and also the extant sloths (pers. obs. RKM). 
Table 1. Cranial measurements (in millimeters) for Parocnus dominicanus and $P$. serus.

\begin{tabular}{|c|c|c|c|c|c|}
\hline \multirow[b]{3}{*}{ Length of rostrum to occipital condyles } & \multirow{2}{*}{ MHD 237} & \multicolumn{2}{|c|}{ P. dominicanus $\left(\mathrm{n}=6^{*}\right)$} & \multicolumn{2}{|c|}{ P. serus $(\mathrm{n}=4)$} \\
\hline & & Mean & St Dev & Mean & St Dev \\
\hline & & 179.3 & \pm 1.8 & 220.3 & \pm 4.0 \\
\hline Nasal opening height & 26.7 & 26.2 & \pm 1.0 & 30.1 & \pm 2.2 \\
\hline Width across jugals/lacrimals & 53.0 & 58.2 & \pm 3.4 & 68.0 & \pm 4.9 \\
\hline Palate length & 67.6 & 71.6 & \pm 3.2 & 89.1 & \pm 3.6 \\
\hline Toothrow length & & 90.7 & \pm 3.3 & 102.3 & \pm 3.6 \\
\hline Breadth of rostrum across canines & & 62.3 & \pm 2.2 & 68.8 & \pm 5.7 \\
\hline Cf1 alveolar width & & 16.1 & \pm 0.3 & 16.2 & \pm 0.7 \\
\hline Cf1 alveolar length & & 13.6 & \pm 1.0 & 15.7 & \pm 0.2 \\
\hline Diastema length & 33.1 & 33.4 & \pm 1.1 & 38.9 & \pm 0.8 \\
\hline Molariform toothrow length (Mf1-Mf4) & 41.3 & 42.9 & \pm 1.4 & 50.1 & \pm 1.8 \\
\hline Mf1 alveolar width & 11.4 & 11.5 & \pm 0.3 & 13.3 & \pm 1.5 \\
\hline Mf1 alveolar length & 9.8 & 10.2 & \pm 0.3 & 12.5 & \pm 0.9 \\
\hline Breadth of palate across Mf1 & 43.9 & 46.6 & \pm 2.0 & 44.1 & \pm 2.3 \\
\hline Breadth of palate between Mf1 & 16.5 & 16.6 & \pm 0.1 & 17.6 & \pm 1.0 \\
\hline Mf2 alveolar width & 15.1 & 14.9 & \pm 0.1 & 16.8 & \pm 0.9 \\
\hline Mf2 alveolar length & 10.5 & 10.5 & \pm 0.2 & 13.0 & \pm 1.3 \\
\hline Mf3 alveolar width & & 13.5 & \pm 0.2 & 15.7 & \pm 1.2 \\
\hline Mf3 alveolar length & & 9.2 & \pm 0.1 & 11.4 & \pm 1.2 \\
\hline Mf4 alveolar width & & 11.5 & \pm 0.2 & 12.8 & \pm 1.0 \\
\hline Mf4 alveolar length & & 7.2 & -- & 7.9 & \pm 0.4 \\
\hline Breadth of postorbital processes at the root of the process & 54.8 & 58.8 & \pm 4.0 & 74.2 & \pm 4.3 \\
\hline Breadth at postorbital constriction & 39.4 & 45.0 & \pm 4.2 & 55.9 & \pm 4.6 \\
\hline Breadth at posterior zygomatic roots (widest part of neurocranium) & 52.2 & 56.5 & \pm 4.6 & 66.4 & \pm 2.5 \\
\hline Width across the occiptal & 71.5 & 76.8 & \pm 2.8 & 90.5 & \pm 5.1 \\
\hline Width across the occipital condyles & 46.5 & 49.3 & \pm 2.2 & 58.0 & \pm 3.3 \\
\hline Foramen magnum height & 22.2 & 21.0 & \pm 1.3 & 20.0 & \pm 1.5 \\
\hline Foramen magnum width & 26.3 & 22.8 & \pm 4.8 & 28.8 & \pm 3.3 \\
\hline Posterior cranium depth: sagittal crest to basisphenoid & 51.5 & 51.5 & -- & 67.8 & \pm 3.7 \\
\hline
\end{tabular}

The nasals of both Hispaniolan species of Parocnus possess an anterior extension along the lateral side, which with the morphology of the maxilla makes the projections appear "prong-like." Such anterior projections from the nasals are not seen in any species of the other Greater Antillean genera. The characterization of this feature cannot be determined for $P$. browni because the nasals of the holotype (AMNH 16877) are damaged and prevent direct comparison. Although the nasomaxillary sutures are absent in $P$. dominicanus types, their location can be determined from inside the nasal cavity because both bones produce a short, ventral projection that also serves as the lateral boundary to part of the vomer.

In dorsal view (Figs. 3A, 11), the temporal lines merge to form a sagittal crest just posterior to a coronal plane connecting the anterior roots of the temporal processes. The crest then diverges at the coronal plane across the posterior roots of the temporal processes to form two lines which deviate laterally before joining with the parieto-occipi- tal crest. This point of union is posterior to that of other specimens of $P$. dominicanus as well as $P$. serus. Otherwise, the union point for $P$. dominicanus is just anterior to the temporal process roots, which is still posterior to that of $P$. serus where the union occurs midway between the postorbital process and the temporal process root. The holotype specimen appears to have a bulbous portion of bone that prevents an earlier union of the temporal lines (Fig. 3A). This appears to be a feature unique to this individual and is not seen in any of the other cranial specimens.

The rostrum of $P$. dominicanus is wider than that of $P$. browni, at least anterior to the root for the jugal. The palate between the molariform toothrows widens slightly posteriorly, is dotted with several smaller foramina, and at the anterior portion exhibits two palatine sulci separated by the midline and each leading to a large, anterior palatine foramen (Fig 3D). The termination of the sulci at each palatine foramen are unevenly positioned with the left side extending to the level of the alveolae for Mf2-3 


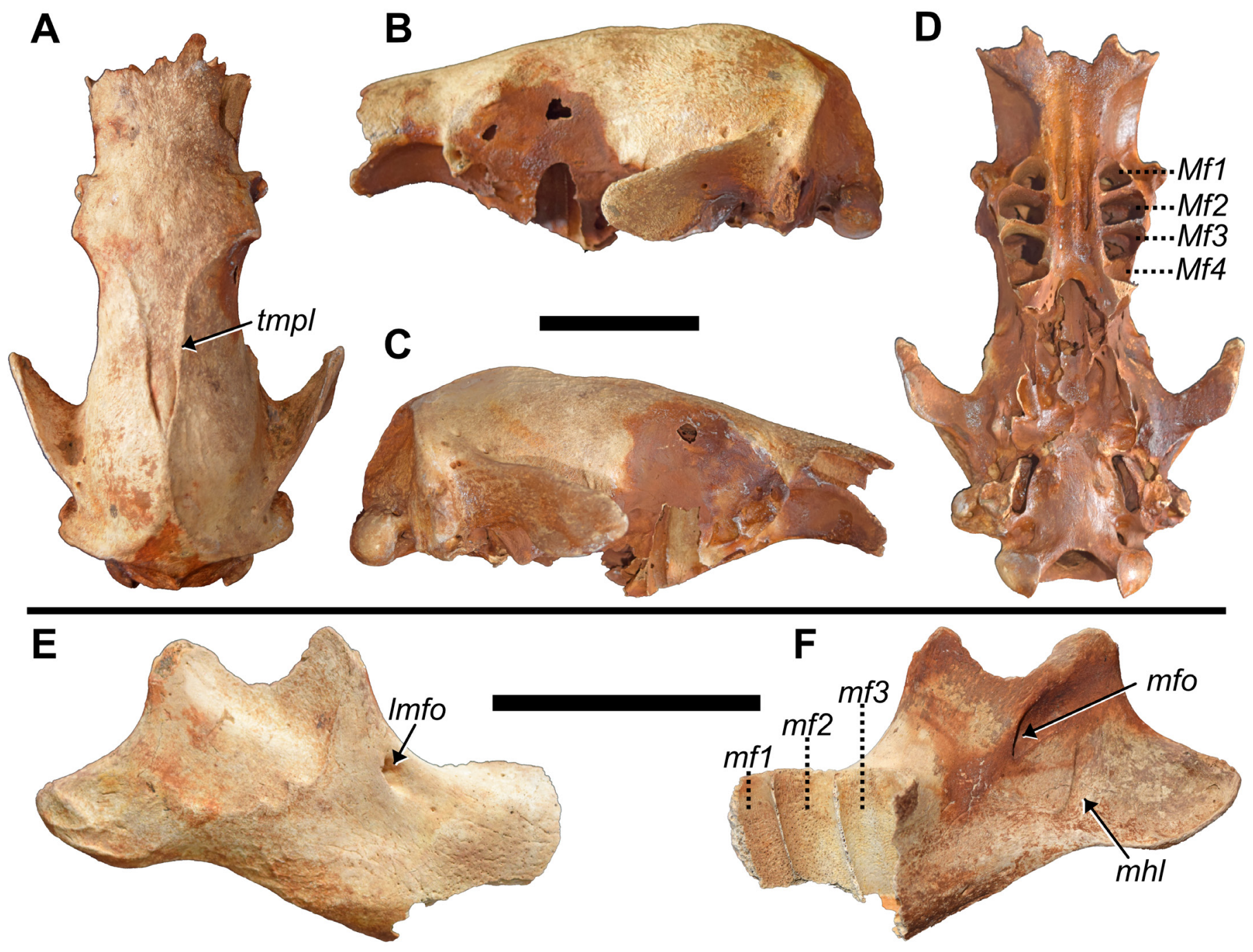

Figure 3. Skull and right mandible of MHD 237 Parocnus dominicanus. Skull shown in A, dorsal, B, left lateral, C, right lateral, and D, ventral views; right mandible shown in E, lateral and F, medialviews. Abbreviations: Imfo, lateral mandibular foramen; Mf, upper molariform; mf, lower molariform; mhl, mylohyoid line; mfo, mandibular foramen; tmpl, temporal line. Scale bars equal $5 \mathrm{~cm}$.

while the right ends at the alveolae for Mf1-2. This is more posterior than that exhibited by $P$. browni, in which the termination is in the middle of the diastema region but similar to that exhibited by Megalocnus at the anterior end of Mf1 (Matthew and Paula Couto 1959; Fischer 1971). In specimens of $P$. serus, the anterior palatine foramen occurs inconsistently along the palate, suggesting that this feature may not be taxonomically diagnostic. The lateral margin of the molariforms presents a convex arc with the Mf2 and Mf3 marking the widest points from the midline. Mf1 alveoli are subtriangular and smaller than the Mf2s, which are rectangular in outline and with the mediolateral long axis angled with respect to the palate.

Mandible: The right dentary, lacking the anterior half and all the teeth, is preserved. The lateral aspects of the alveoli for the molariforms (mf1-mf3) are partially preserved; both coronoid and condyloid processes are incomplete
(Fig. 3E, F). Although the mandibular condyle is absent, its placement would have been elevated above the plane of the toothrow, as is also seen in P. serus. The posterior ramus is complete and displays muscle scars for the various slips of m. massetericus (Fig. 3E; Naples 1985, 1989; Naples and McAfee 2012, 2014). The posterior ramus is separated from the body by a distinct notch due to the ventral bowing of the body to accommodate the molariforms. This bowing and notching is more pronounced than in P. browni but is equal to that of $P$. serus. In lateral view, attachment scarring for the zygomaticomandibularis and masseter is evident. The scarring for zygomaticomandibularis extends ventrally from the coronoid process in a straight line and begins to curve posteroventrally at the level of the lateral mandibular foramen and toothrow but is well posterior to the lateral mandibular foramen. This separation is the same in P. serus but in P. browni, the vertical portion of 
the attachment scar is just posterior to the foramen with almost no separation. The lateral mandibular foramen is positioned just posterior to the anterior margin of the base of the coronoid process. On the medial surface, the mylohyoid groove is separate from the mandibular foramen and forms a ' $\mathrm{j}$ ' shape (Fig. $3 \mathrm{~F}$ ); this condition is also the same in $P$. browni and P. serus.

Thoracic Vertebrae: In the skeletal specimen of P. browni described by Fischer (1971), the number of thoracic vertebral elements was estimated to be 21 or 22 , which is close to that of Choloepus and Hapalops (22-24: Scott 1903; Gaudin 1999; Hautier et al. 2010). However, the number of thoracic vertebrae could be less given the variable ranges between $16-18$ thoracics that have been noted for other fossil sloths (Amson et al. 2015b). Of the five holotype vertebrae in Figure 4, four likely represent the middle thoracic region, whereas the final is certainly from the posterior region, based on features described by Fischer (1971). There are no discernable xenarthrous articulations on any of the vertebrae.

For the anterior to middle thoracic vertebrae (Fig. 4A-H), the centra have the characteristic rounded, triangular shape when viewed cranially and caudally, and there are two small facets found on the dorsolateral margins of the caudal centrum surface. The vertebral canals are ovate, with the long axis transversely oriented. The transverse processes are
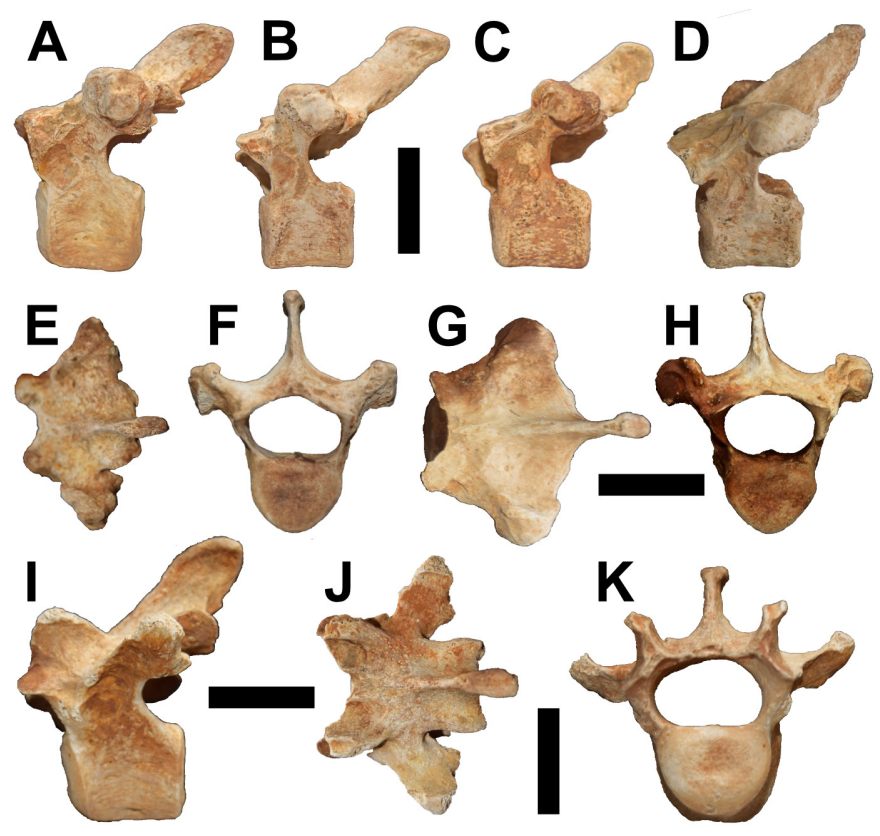

Figure 4. Holotype vertebrae of MHD 237 Parocnus dominicanus from Padre Nuestro. Thoracic \#1 in A, left lateral and dorsal E, views; thoracic \#2 in B, left lateral and F, cranial views; thoracic \#3 in C, left lateral and G, dorsal views; thoracic \#4 in D, left lateral and $\mathrm{H}$, cranial views; and Thoracic \#5 in I, left lateral, J, dorsal, and K, cranial views. Scale bars equal to $2 \mathrm{~cm}$. short, project dorsolateral from the laminar plane, and bear convexly rounded articular facets that in this thoracic series are laterally directed. Each transverse process also bears a small cranially directed process along its cranial margin that is separate from the rib articular facet. This process is likely associated with the intertransverse ligaments. The pedicles are strongly indented along their cranial margin to form part of the articulation with the heads of the ribs. The caudodistally angled spinous processes are long with an enlargement of the distal end. The pre- and postzygapophyseal articular facets, located immediately medial to the pedicels, are flat and within the same craniocaudal plane.

The lone vertebra from the posterior thoracic section (Fig. 4I-K) has a range of morphological characters reminiscent of both thoracic and lumbar vertebra, but is decidedly thoracic due to the presence of rib articulations. However, it differs from other thoracic vertebrae in several respects. The spinous process has a distal enlargement but overall is shorter and is less caudally projected. The transverse processes are a little longer but extend caudolaterally; the costal facets are still convex. The zygapophyses are split into medial and lateral components or facets. The laminae caudal to the transverse processes are medially constricted and bear more distinct medial postzygapophyses with convex facets. This is complementary to the cranial end of the next posterior vertebra where the medial prezygapophyses are medial on the lamina with respect to the pedicles and are concave with a mediodorsal facing surface. The lateral prezygapophyses are lateral-to-even with the pedicles and are dorsolaterally facing, while the lateral postzygapophyses can be found on the ventral surface of the caudal portion of the transverse processes and facing ventromedial. The centrum is ovate instead of triangular and the small facets along the dorsolateral margin are no longer present. This matches with the descriptions given by Fischer (1971) for vertebrae of the posterior thoracic region of $P$. browni.

Rib 1: The neck is short and is nearly as thick as the head, with a slight indentation on the dorsal margin that distinguishes the costal tubercle from the head (Fig. 5). The articulation on the rib head is ovate but convexly folded along the middle to give the appearance of two continuous surfaces. As in P. serus and P. browni, a prominent lateral tubercle is present toward the point where the costal rib fuses with the ossified sternal cartilage, but in P. dominicanus this tubercle is reduced and gives the sternal end a more uniform width relative to that of the shaft. For $P$. dominicanus, the reduction in the sternal tubercle also gives the diaphysis a bowed and twisted appearance when caudally viewed (Fig. 5C, D), which is not exhibited by $P$. serus. The sternal tubercle appears more caudally positioned than in P. serus where it is instead moderately directed towards lateral. Across from the sternal tubercle on the medial margin is another smaller tu- 

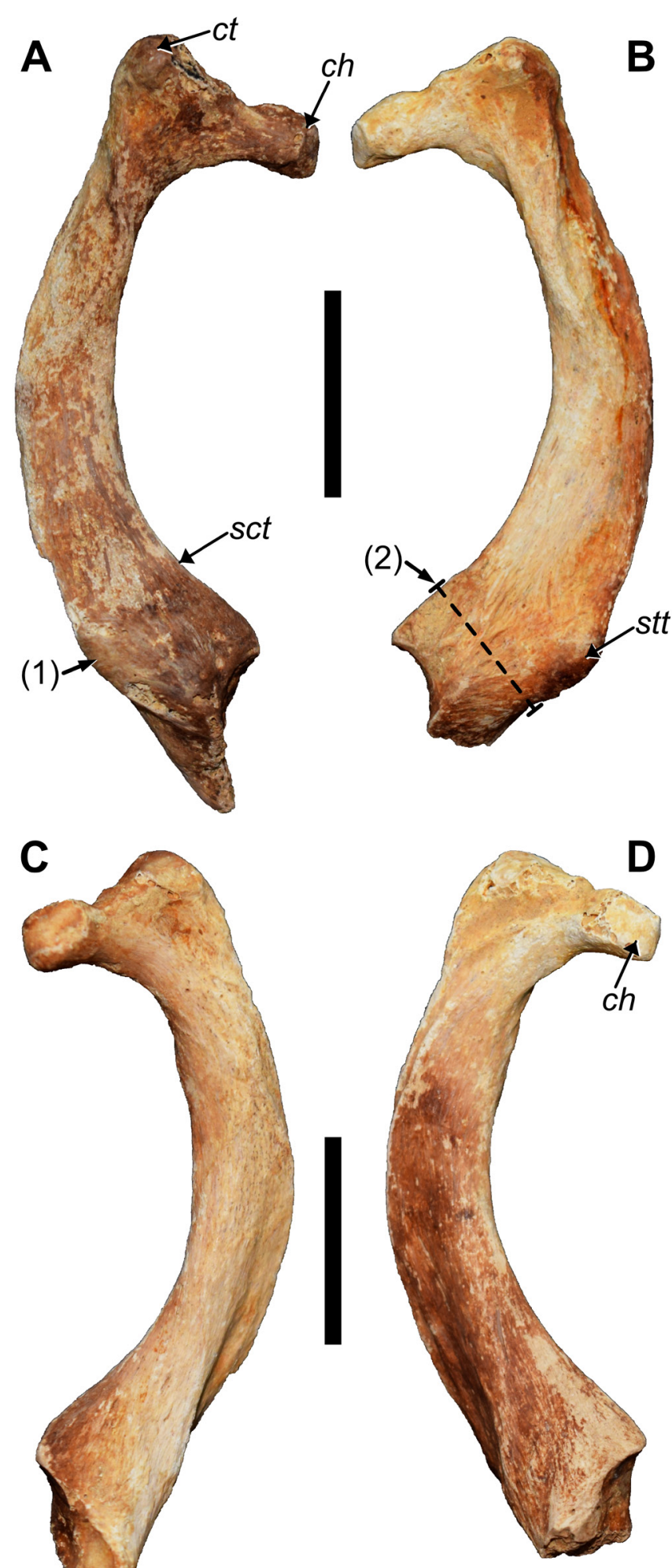

Figure 5. Right and left first ribs of MHD 237 Parocnus dominicanus from Padre Nuestro. Right rib in: A, cranial and C, caudal views, and left rib in: $B$, cranial and $D$, caudal views. Abbreviations: ch, costal rib head; ct, costal rib tubercle; sct, scalene tubercle; stt, sternal tubercle. Diagnostic characters: 1 , sternal tubercle reduced, located more caudally, and deflected away from the diaphysis, 2, sternal end of rib 1 is narrow. Scale bars equal $5 \mathrm{~cm}$. bercle (Fig. 5A), likely corresponding to the scalene tubercle, and which is reduced in size compared to that of P. serus.

The inner surfaces of the distal ends exhibit two articular surfaces for contact with the manubrium. The dorsal facet is a rounded depression, while the ventral is slightly concave, triangular, and extends onto the distal portion retained in the right first rib (Fig. 5C).

Scapula: Both scapulae are incomplete but together account for the majority of aspects that each individually lacks. The left scapula is nearly complete (Fig. 6A) but lacks the anterior extension of the spine and the coraco-acromial complex, which the right side retains (Fig. 6B, C). Part of the posterior border inferior to the spine and the fossae floors are also absent in both scapulae, but more is preserved in the paratype (MHD 350: see figure $4 \mathrm{f}$ in McAfee \& Beery 2021). The secondary scapular spine is present, but not prominent, and the teres major fossa is visible but not strongly developed. The acromion and coracoid processes are fused into one complex, a feature also seen in the other Parocnus species, and sloths in general. The coraco-scapular foramen is incomplete in all the $P$. dominicanus specimens, but the anterior margins are relatively preserved to indicate its location just dorsal to the glenoid fossa (Fig. 6A, C).

The glenoid fossa is ovate, with the inferior portion slightly wider than the superior, and the dimensions are smaller than those for P. serus (Tab. 2). The exception is UF-VP 16997. This specimen of $\mathrm{P}$. serus has glenoid values similar to those of $P$. dominicanus, but the shape of the scapular borders gives the impression that this specimen is younger and that the size similarities may be an ontogenetic artefact. The differences in the specimen likely fall within the variability noted for P. serus by McAfee and Beery (2021).

Humerus: Complete, paired humeri without an entepicondylar foramen, characteristic of Parocnus, are preserved. The diaphyses are medially bowed, such that when transected by a longitudinal plane, the humeral head is unevenly divided so that more of the humeral head is located on the medial side of the plane (Fig. 7D, E). This contrasts with $P$. serus and $P$. browni in which the diaphysis is straighter and so the head occupies both sides of the longitudinal plane with near equality (Fig. 7F). The bowed appearance is enhanced by the prominent narrowing of the diaphysis just distal to the tubercles. The most proximal margin of the lesser tubercle is situated distal to that of the greater tubercle in P. dominicanus (Fig. 7A, B), but the two are evenly aligned in P. serus (Fig. 7C).

The deltopectoral shelf has a lateral extension at its midshaft termination, which exhibits two shallow fossae separated by the brachiocephalicus crest (Amson et al. 2015a). These fossae are related to equal sized muscle attachment for $m$. pectoralis (medial) and $m$. deltoideus (lateral) (Toledo et al. 2013). In P. serus, the two fossae are 
Figure 6. Right and left scapulae of MHD 237 Parocnus dominicanus from Padre Nuestro. Right scapula in: A, anterior/cranial and $B$, lateral views, and C, left scapula in lateral view. Abbreviations: csf, coracoscapula foramen; gf, glenoid fossa; ssp, secondary scapular spine, tmf, teres major fossa.
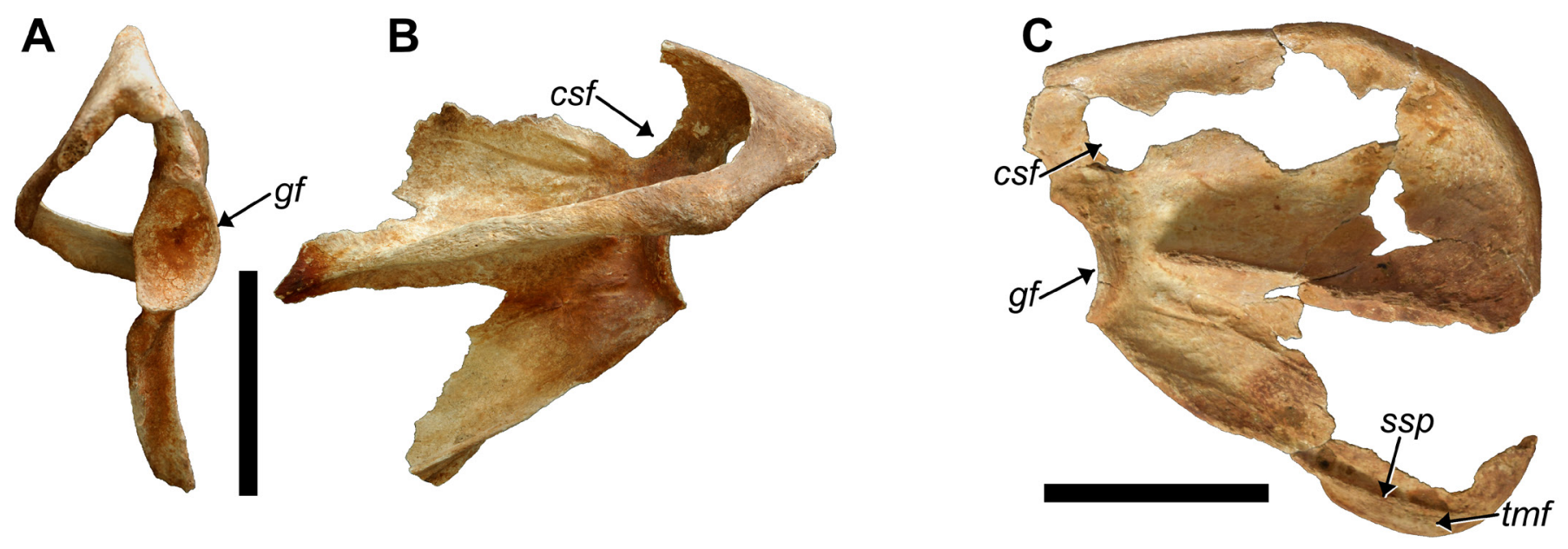

present, but they are unequal with the medial larger than the lateral fossa, as expected for a larger animal; this feature is broken in the holotype (Fig. 7C, F). The lateral border of the deltopectoral shelf in both $P$. serus and P. dominicanus (as well as Megalocnus rodens) occupies or nearly occupies the same parasagittal plane as the lateral epicondyle, while in $P$. browni the crest is not as well-developed and does not extend laterally in the same plane.

In posterior view, the proximal half of the humerus in P. dominicanus does not exhibit strong muscle scars. The pattern and location of theses scars is the same as in P. serus and $P$. browni, with their reduced development, likely a result of the size difference between the species (Tab. 3). The overall anatomy of the distal half of the humerus does not significantly differ between the Parocnus species.

Pelvis: This specimen represents the most complete pelvis known for any species of Parocnus. It is missing aspects from both iliac blades, and the pubic and ischial rami are broken but such that the pubic symphysis and part of those rami exist as a singular element, separate from the rest (Fig. 8C). Each iliac blade forms a rounded, convex arc going lateral from the tuber sacralis toward the (absent) dorsal spine, which is consistent with the specimens described by Fischer (1971) as P. browni and M. rodens. This morphology is also in contrast to the sharper, more angular features exhibited by Acratocnus and Neocnus (McAfee and Rimoli 2019). The morphology of the ilium from the acetabulum to the cranial ventral iliac spine differs from the transverse lateral extension exhibited by Megalocnus and Acratocnus by having a more dorsolateral extension, although it is more laterally angled than that exhibited by Neocnus (McAfee and Rimoli 2019). The caudal ventral iliac spines are small tubercles situated just cranial to the acetabulum in the pelvises of Acratocnus (pers. obs), Megalocnus (Fischer 1971), and Neocnus (McAfee and Rimoli 2019). The same positioning appears to be true for the holotype and is confirmed by a more prominent occurrence in the paratype MHD 238.

The presence and location of the cranial ventral iliac spine is somewhat uncertain because the lateral-most points of the iliac blades are broken in all specimens, where it is assumed to have occurred. The caudal margin of each iliac blade is worth noting because it does not present a straight-

Table 2. Scapulae measurements (in millimeters) for the holotype of Parocnus dominicanus versus P. serus.

\begin{tabular}{|c|c|c|c|c|}
\hline \multirow[b]{3}{*}{ Length of 2 nd spine (to base of glenoid) } & \multicolumn{2}{|c|}{ P. dominicanus } & \multicolumn{2}{|c|}{ P. serus $(\mathrm{n}=5)$} \\
\hline & MHD 237 (L) & MHD 237 (R) & Mean & St Dev \\
\hline & & & 116.6 & \pm 4.3 \\
\hline Long axis of glenoid & 28.9 & 27.9 & 36.5 & \pm 4.2 \\
\hline Wide axis of glenoid & 18.4 & 18.7 & 24.3 & \pm 2.9 \\
\hline Length from Coraco-acromion to root of spine & & & 165.6 & \pm 3.5 \\
\hline Posterior width of infraspinous fossa & 45.8 & & 54.1 & \pm 10.1 \\
\hline Maximum width of teres fossa & & & 15.3 & \pm 2.4 \\
\hline Length: vertebral border to glenoid along supscapular ridge & 95.9 & & 113.9 & \pm 7.6 \\
\hline Width of infraglenoid tubercle & 5.5 & 6.3 & 9.3 & \pm 1.4 \\
\hline
\end{tabular}



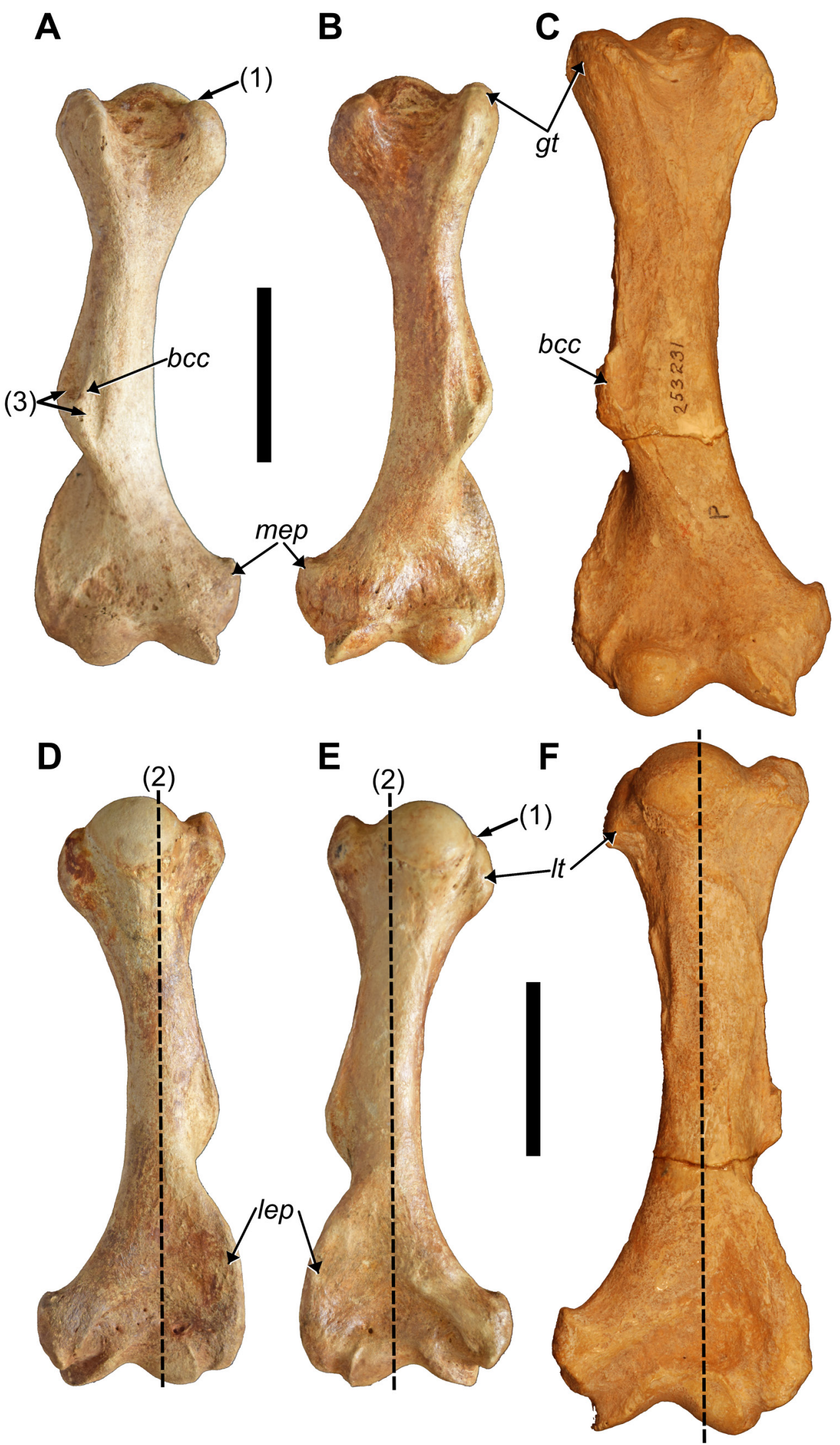

Figure 7. Right and left humeri of MHD 247 Parocnus dominicanus and comparison to the paratype right humerus of $P$. serus. Right humerus of $P$. dominicanus in $A$, anterior and $D$, posterior views; left humerus of $P$. dominicanus in $B$, anterior and $E$, posterior views; right humerus of $P$. serus (USNM PAL 700637) in C, anterior and F, posterior views. Abbreviations: bcc, brachiocephalic crest; gt, greater tubercle; lep, lateral epicondyle; It, lesser tubercle; mep, medial epicondyle. Diagnostic characters: 1, proximal margin of the lesser tubercle is distal to that of the greater tubercle; 2, humeral head medially offset from longitudinal plane of the diaphysis; 3 , medial and lateral fossae of the deltopectoral crest are equal in size. Scale bars equal to $5 \mathrm{~cm}$. 
Table 3. Humerus measurements (in millimeters) for Parocnus dominicanus and P. serus.

\begin{tabular}{|c|c|c|c|c|c|c|}
\hline & \multirow[t]{2}{*}{ MHD 237 (L) } & \multirow[t]{2}{*}{ MHD 237 (R) } & \multicolumn{2}{|c|}{ P. dominicanus $\left(\mathrm{n}=11^{*}\right)$} & \multicolumn{2}{|c|}{ P. serus $(\mathrm{n}=7)$} \\
\hline & & & Mean & St. Dev & Mean & St. Dev \\
\hline Total Length & 166.4 & 165.9 & 162.4 & \pm 5.6 & 189.3 & \pm 12.2 \\
\hline Max width across both tubercles & 47.5 & 46.9 & 49.5 & \pm 1.8 & 56.7 & \pm 7.5 \\
\hline Width across lesser tubercle & 24.7 & 23.6 & 23.1 & \pm 1.8 & 24.0 & \pm 2.9 \\
\hline Max epicondylar width & 59.7 & 59.8 & 58.8 & \pm 2.2 & 70.4 & \pm 5.8 \\
\hline Medial Epicondyle height & 22.2 & 22.3 & 24.2 & \pm 2.5 & 26.8 & \pm 3.2 \\
\hline Medial Epicondyle width & 17.2 & 15.7 & 16.8 & \pm 1.8 & 22.4 & \pm 2.4 \\
\hline Max width across condyles (distal) & 41.2 & 40.6 & 39.7 & \pm 2.5 & 46.8 & \pm 4.6 \\
\hline Anterior condyle width & 19.4 & 21.1 & 20.3 & \pm 1.5 & 36.2 & \pm 8.6 \\
\hline
\end{tabular}

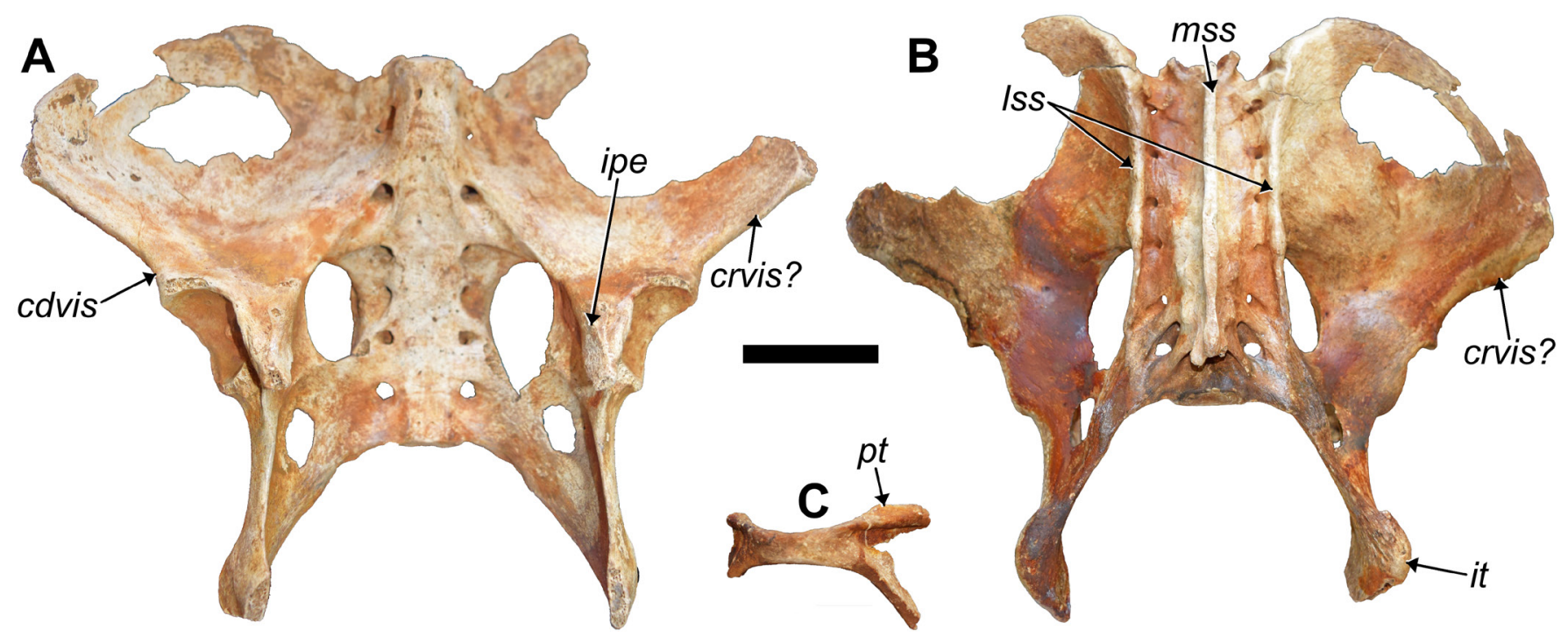

Figure 8. Pelvis and pubic symphysis of MHD 237 Parocnus dominicanus from Padre Nuestro. Pelvis shown in A, ventral/ cranial and B, dorsal/caudal views; C, associated pubic symphysis region shown in anterior/cranial view. Abbreviations: cdvis, caudal ventral iliac spine; crvis?, cranial ventral iliac spine (assumed); ipe, iliopectineal eminence; it, ischial tuberosity; Iss, lateral sacral spines; mss, median sacral spine; pt, pubic tubercle. Scale bars equal $5 \mathrm{~cm}$.

line surface but has an anteriorly directed bulge about midway between the acetabulum and the lateralmost point (Fig. 8), which is a feature not evident in any of the other Caribbean sloths. Damage to the lateralmost points of the iliac blades makes it impossible to rule out that the bulge on the caudal margin may represent the cranial ventral iliac spine and the attachment of the rectus femoris muscle.

The acetabulum is subcircular and the lunate surface within is ventrally separated by an incisive notch running between the ischial and pubic cornuses. White and MacPhee (2001), presumably using elements collected by Miller, listed the lack of such a gap in the acetabular rim as a feature of $P$. serus, while Fischer (1971) noted the existence of the gap for $P$. browni. The variability in this feature may be age related, as demonstrated by a greater range of pelvic specimens assigned to Acratocnus (pers. obs.: RKM). The iliopectineal eminence (pecten pubis), which represents the attachment of the $m$. pectineus, is evident on both sides and sits medial to the acetabulum along the inner rim of the pelvis. Caudally, and along the innermost surface of the same region, there is a wide groove running between the ischiosciatic foramen and the posterior margin of the obturator foramen, likely indicating the pathway of the obturator nerve and vessels.

The ischial ramus is broadened by bony extensions to the terminal sacral vertebrae, and those extensions form the caudal margin of the ischiosciatic foramen. The holotype exhibits damage in this area on both sides, giving the impression that a foramen is present, but MHD 238 confirms that those are artificial features. The ischial rami terminate as distinct ischial tuberosities for attachment of the poster- 
ior thigh muscles (Fig. 8B). A crest on the caudal margin extending between the ischial tuberosity and the last/seventh sacral vertebra is visible on the lateral surface, which increases in craniocaudal height as it nears the sacrum and the termination of the lateral sacral crest.

The sacrum consists of seven fused vertebrae with lateral alar extensions contacting the ilial and ischial elements, resulting in six sets of sacral foramina. In MHD 238, there are eight fused vertebrae, although the first in the series occurs without alar extensions to the ilium and therefore represents a fused lumbar or a pre-iliac synsacral vertebra (sensu Galliari and Carlini 2019). In dorsal view, three crests are clearly defined (one median sacral and two lateral sacral crests). The median sacral crest (Fig. 8B) is distinct and raised with respect to the laminae, which is more akin to condition exhibited by Megalocnus (Fischer 1971), but unlike the flattened condition in Acratocnus and Neocnus (McAfee and Rimoli 2019). The lateral sacral crests are most evident in the iliac region and are stronger than that exhibited by Megalocnus; the crests are almost non-existent in the iliac region in Acratocnus and Neocnus. The lateral crest suddenly narrows posterior to the alar contribution from the four sacrals. The caudal continuation of the crest forms the mediodorsal margin of the ischiosciatic foramen and then trends caudolateral into the caudal margin of the expanded ischial ramus. Overall, the lateral sacral crests are slightly more curved (laterally concave) than that exhibited by Megalocnus and are distinct from Acratocnus and Neocnus where they taper caudally from lateral to medial.

Femur: The morphology of the paired femora is on par with the characters attributed to Parocnus (see White and MacPhee 2001), but the lack of complete, adult, and accessible femora for $P$. serus makes detailed comparisons impossible at this time. Overall, there is little to distinguish the femora of $P$. dominicanus from $P$. serus, and in most ways the morphology is what is expected from a reduction in size (Tab. 4). The greater trochanter is a little smaller, such that it is closer to the same level as the femoral head rather than being above it (Fig. 9A, B). The lesser trochanter, which is characteristically underdeveloped in Parocnus overall, is less developed than that of $P$. serus; it resembles the reduced development of $P$. browni (specimen Ma. 5/67: Fischer 1971). The third trochanter is prominent and confluent with the greater trochanter, although the indentation created by the development of those trochanters is not as pronounced in $P$. dominicanus. The existence of a trochanteric fossa (Fig. 9A, D) on the posterior surface has not previously been recognized, but such a feature is evident in $P$. serus and $P$. dominicanus, which serves as a unique character to distinguish these species from $P$. browni, as well as to all other Caribbean sloth species. The fovea capitis is not centered on the femoral head but is posteriorly displaced, as in many large-bodied ground sloths, and creates an indentation with

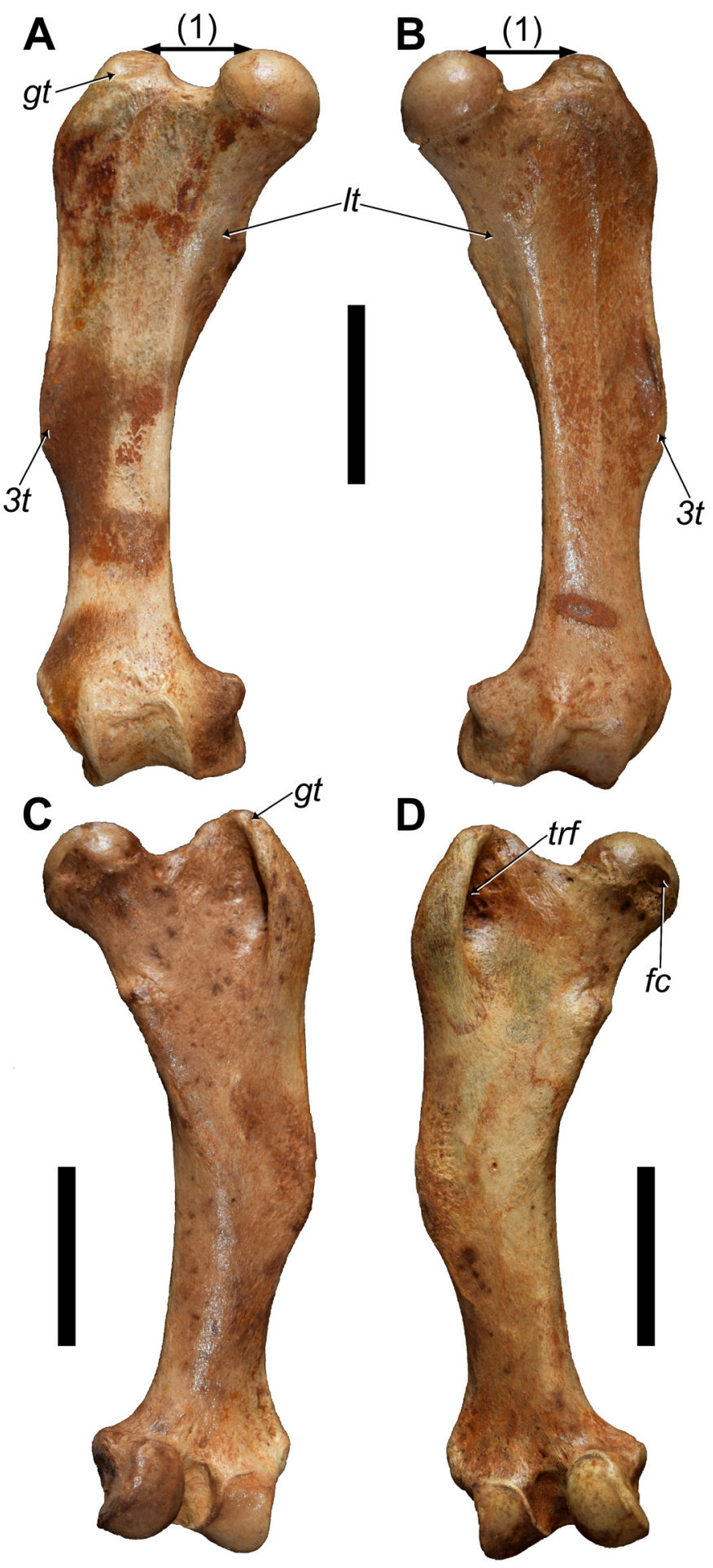

Figure 9. Right and left femora of MHD 247 Parocnus dominicanus from Padre Nuestro. Right femur in $A$, anterior and $C$, posterior views, and left femur in $B$, anterior and D, posterior views. Abbreviations: $3 \mathrm{t}$, third trochanter; $\mathrm{fc}$, fovea capitis; gt, greater trochanter; It, lesser trochanter; trf, trochanteric fossa. Diagnostic characters: 1 , femoral head and greater trochanter of equal height. Scale bars equal to $5 \mathrm{~cm}$. 
Table 4. Measurement (in millimeters) for the hind limb elements of Parocnus dominicanus and P. serus.

\begin{tabular}{|c|c|c|c|c|c|c|}
\hline \multirow[b]{2}{*}{ Femur } & \multirow[t]{2}{*}{ MHD 237 (L) } & \multirow[t]{2}{*}{ MHD $237(\mathrm{R})$} & \multicolumn{2}{|c|}{ P. dominicanus $\left(\mathrm{n}=18^{*}\right)$} & \multirow{2}{*}{\multicolumn{2}{|c|}{$\begin{array}{l}\text { P. serus MNHNSD } \\
\text { FOS } 25.3353(\mathrm{R})\end{array}$}} \\
\hline & & & \multicolumn{2}{|c|}{ Mean St. Dev } & & \\
\hline Total length & 200.4 & 200.3 & 197.9 & \pm 10.9 & \multicolumn{2}{|l|}{$240^{\wedge}$} \\
\hline Circumference of head & $86^{\wedge}$ & 96.0 & 100.2 & \pm 17.2 & \multicolumn{2}{|l|}{118.0} \\
\hline AP depth of lesser trochanter & 52.0 & 51.1 & 52.1 & \pm 3.2 & \multicolumn{2}{|l|}{67.4} \\
\hline AP depth of 3 rd trochanter & 37.9 & 38.9 & 39.4 & \pm 2.4 & \multicolumn{2}{|l|}{50.7} \\
\hline Epicondylar width & 54.8 & 55.5 & 55.6 & \pm 3.5 & \multicolumn{2}{|l|}{$62^{\wedge}$} \\
\hline Anterior condyle width & 20.5 & 19.9 & 22.5 & \pm 2.9 & \multicolumn{2}{|l|}{29.0} \\
\hline Posterior condyle width & 44.7 & 44.8 & 44.3 & \pm 2.6 & \multicolumn{2}{|l|}{53.4} \\
\hline Height of greater trochanter & $56^{\wedge}$ & 53.3 & 58.3 & \pm 4.1 & \multicolumn{2}{|l|}{64.5} \\
\hline Depth of greater trochanter & 28.1 & 28.5 & 28.7 & \pm 10.8 & \multicolumn{2}{|l|}{35.3} \\
\hline Depth of 3rd trochanter & 10.0 & 10.2 & 10.1 & \pm 1.2 & \multicolumn{2}{|l|}{13.7} \\
\hline Distance across trochanters & 66.9 & 66.8 & 66.6 & \pm 5.3 & \multicolumn{2}{|l|}{84.6} \\
\hline \multicolumn{7}{|c|}{$*_{\text {includes Holotype specimens, }}^{\wedge}$ represents an estimated measurement } \\
\hline \multirow[b]{2}{*}{ Tibia } & \multirow[t]{2}{*}{ MHD $237(\mathrm{~L})$} & \multirow[t]{2}{*}{ MHD $237(\mathrm{R})$} & \multicolumn{2}{|c|}{ P. dominicanus $\left(\mathrm{n}=14^{*}\right)$} & \multicolumn{2}{|c|}{ P. $\operatorname{serus}(\mathrm{n}=4)$} \\
\hline & & & Mean & St. Dev & Average & St. Dev \\
\hline Total length & 125.8 & 126.4 & 120.6 & \pm 5.1 & 138.2 & \pm 13.9 \\
\hline Length of proximal fibular articular surface & 6.2 & 5.0 & 5.7 & \pm 0.6 & 18.6 & -- \\
\hline Width of proximal fibular articular surface & 11.9 & 17.2 & 15.6 & \pm 2.5 & 9.5 & \pm 2.5 \\
\hline Length of distal articular surface (astragular) & 23.9 & 24.5 & 23.6 & \pm 2.4 & 28.7 & \pm 4.7 \\
\hline Width of distal articular surface (astragular) & 22.7 & 22.7 & 22.6 & \pm 2.3 & 30.2 & \pm 3.2 \\
\hline Length of distal fibular articular surface & 13.9 & 13.4 & 12.7 & \pm 1.0 & 16.7 & \pm 1.5 \\
\hline Width of distal fibular articular surface & 9.7 & 11.3 & 8.9 & \pm 1.5 & 10.7 & \pm 0.9 \\
\hline Proximal epicondylar width & 45.1 & 46.0 & 43.4 & \pm 2.9 & 53.7 & \pm 4.6 \\
\hline Distal epicondylar width & 35.4 & 37.0 & 33.3 & \pm 2.6 & 42.4 & \pm 5.2 \\
\hline Medial condyle length & 29.0 & 29.2 & 25.1 & \pm 3.3 & 32.9 & \pm 3.8 \\
\hline Medial condyle width & 22.2 & 20.4 & 21.6 & \pm 2.0 & 19.8 & \pm 11.9 \\
\hline Lateral condyle length & 20.6 & 24.4 & 19.8 & \pm 3.1 & 22.5 & \pm 4.0 \\
\hline Lateral condyle width & 19.7 & 19.7 & 19.0 & \pm 3.2 & 21.3 & \pm 3.3 \\
\hline
\end{tabular}

\begin{tabular}{|c|c|c|c|c|}
\hline \multirow[b]{2}{*}{ Fibula } & \multirow[t]{2}{*}{ MHD 237 (R) } & \multicolumn{2}{|c|}{ P. dominicanus $\left(\mathrm{n}=14^{*}\right)$} & \multirow{2}{*}{$\begin{array}{l}\text { P. serus } \\
\text { USNM } 299612 \text { (L) }\end{array}$} \\
\hline & & Mean & St. Dev & \\
\hline Total length & 119.3 & 117.6 & \pm 4.1 & 133.8 \\
\hline Length of proximal articular surface & 9.3 & 8.6 & \pm 1.4 & 22.4 \\
\hline Width of proximal articular surface & 21.8 & 17.5 & \pm 2.8 & 9.8 \\
\hline Height of distal tibial articular facet & 9.5 & 8.2 & \pm 0.8 & 9.4 \\
\hline Length of distal tibial articular facet & 12.7 & 11.4 & \pm 1.8 & 14.2 \\
\hline Length of distal articular surface (astragular) & 14.8 & 13.7 & \pm 1.6 & 19.8 \\
\hline Height of distal articular surface (astragular) & 16.6 & 18.6 & \pm 1.4 & 19.4 \\
\hline Width of distal end & 26.0 & 24.6 & \pm 2.2 & 27.2 \\
\hline Depth of lateral malleolus & 19.9 & 17.9 & \pm 1.4 & 18.1 \\
\hline Width of proximal end & 22.6 & 22.0 & \pm 2.3 & 17.1 \\
\hline
\end{tabular}


the circumferential margin of the femoral head (Fig. 9A, C, D). The femoral shaft distal to the third trochanter strongly narrows. The femoral condyles are continuous with the articular surface for the patella, and as is typical for sloths, the medial condyle is larger than the lateral.
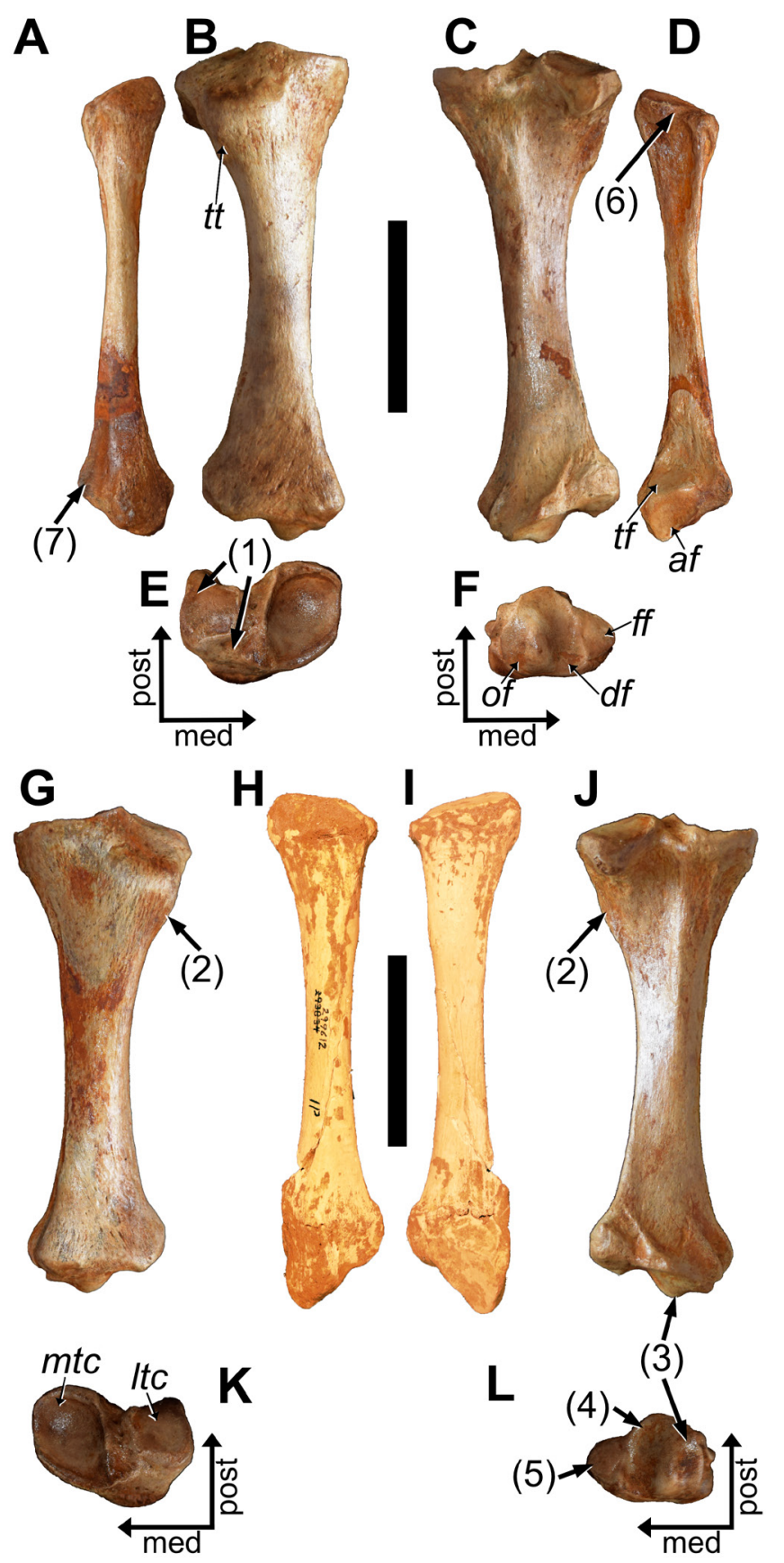

Tibia: In proximal view (Fig. 10E, K), and compared to P. serus, the medial tibial condyle exhibits a greater extension of the anterolateral region, and the anterior margin of the lateral tibial condyle is positioned or begins more posteriorly. In addition, the lateral tibial condyle slopes distolaterally, rather than being flattened, and the posterior surface from the lateral tibial condyle for the $m$. popliteus and its sesamoid is less laterally positioned and angled than in P. serus. In anterior view, the tibial tuberosity is more distally positioned from the tibial plateau than in $P$. serus. In both species, the lateral-most portion of the tibial tuberosity presents as a small protrusion from the diaphysis that can be seen in anterior and posterior views (Fig. 10G, $\mathrm{J}$ ), but the protrusion is smaller in $P$. dominicanus and does not continue as a crest to the posterior surface in P. serus. It is uncertain what muscle(s) attached to the crest, but the distal-most portion remains visible posteriorly when the fibula is in articulation.

At the distal end of the posterior tibia, the medial surface exhibits the trochlear groove for muscle tendons but there is also a groove on the lateral side. A lateral groove exists in $P$. serus but the surrounding features (specifically the laterally placed knob (tibial lateral malleolus) for articulation with the distal fibula and the crest of bone medial it that runs proximolateral from the posterior-most point of the distal astragalar articular surfaces) are not as well developed as those in $P$. dominicanus.

On the distal surface, the articular projection separating the discoid (lateral) and odontoid (medial) surfaces for the astragalus is more prominent in $P$. dominicanus (Fig. 10F, L). The discoid articular facet exhibits a greater degree of concavity than in P. serus. Lateral to this surface, the fibular articular surface is mediolaterally widened to give the surface a more squared appearance, whereas it is more rectilinear in $P$. serus.

Fibula: Unlike Acratocnus, the fibulae of the two Hispaniola Parocnus species possess straight diaphyses (Fig. $10 \mathrm{~A}, \mathrm{D}, \mathrm{H}, \mathrm{I})$. The proximal end with the articular surface for the tibia is obliquely oriented along the anteroposterior axis, with the slope trending posterodistal. The inclination is steeper or more raised in $P$. dominicanus, which is similar to that of $P$. browni. Both $P$. dominicanus and $P$. serus exhibit an indentation along the medial margin, but the placement

Figure 10. Tibiae and right fibula of MHD 247 Parocnus dominicanus and comparison to the paratype left fibula of Parocnus serus. For P. dominicanus: right fibula in A, medial and D, lateral views; right tibia in B, anterior, C, posterior, E, proximal, and F, distal views; left tibia in $\mathrm{G}$, anterior, J, posterior, K, proximal, and $\mathrm{L}$, distal views. The holotype of $P$. serus (USNM PAL 299612) is a left fibula in $\mathrm{H}$, lateral and I, medial views. Abbreviations: af, astragular facet; df, discoid facet; ff, fibular facet; Itc, lateral tibial condyle; mtc, medial tibial condyle; of, odontoid facet; tt, tibial tuberosity. Diagnostic characters: 1 , lateral tibial condyle posteriorly displaced and distolaterally sloped; 2, tibial tuberosity positioned more distal to the tibial plateau and with a more prominent lateral protrusion; 3, discoid and odontoid facets with a prominent separation; 4, discoid facet more concave; 5, distal fibular articular facet more squared; 6, fibular head incline and its medial margin indented at the anteroposterior midpoint; 7 , lateral malleolus of the fibula with a prominent posterior flange bearing a tuberosity and distinct tendon groove. Scale bars equal to $5 \mathrm{~cm}$. 
along the anteroposterior axis differs. In $P$. dominicanus, the indentation occurs near the middle (Fig. 10D) while in $P$. serus it is nearer to the posterior end. This affects the shape of the articular surface, which is more uniform in P. serus as the surface does not extend much past the indentation, but it does extend quite a bit further in $P$. dominicanus. The indentation continues distally as a wide groove along the medial surface of the fibula that is more prominent in $P$. dominicanus. When viewed proximally, $P$. dominicanus has a more prominent lateral bulge, and the proximal end is not as anteroposteriorly wide as the distal end. The bulge is not as evident in $P$. serus, and the overall proximal end is equal to or slightly larger than the distal end as it is not visible from a distal view.

On the distal end, the lateral malleolus has a more prominent posterior flange than that of $P$. serus, which has a more developed lateral malleolus tuberosity and a well-defined tendon groove along its posterior surface. The astragalar articulation on the medial surface consists of two facets, one facing proximally and the other distal to the first that faces medially (Fig. 10D). The inclination of the proximal facet is the same in both taxa, but the distal facet in $P$. dominicanus is not as vertically oriented so that the angle between the two is nearly $90^{\circ}$. The angle between the two astragular facets in P. serus is slightly obtuse.

\section{Paratypes}

Crania (MHD 347, 351, 411, 412): The associated paratype cranial specimens exhibit different levels of completeness (Fig. 11A-H), but overall conform to the morphology to be considered conspecific. The paratypes all demonstrate a considerable degree of pneumatization of the cranium, consistent with that known for other fossil sloths (Boscaini et al. 2018). Jugals are also absent for these specimens, and any isolated jugals that were recovered do not correspond to the morphology established with $P$. browni (Taboada et al. 2007). The pterygoid processes are also broken/missing.

The dental alveoli (Fig. 11B, F) match the morphology described in the holotype for Mf1 and Mf2. The Cf1 alveoli are subtriangular with equal sides like the Mf1 alveoli but are larger and with slight protrusions of the margins that would impact tooth shape (i.e., create grooves). The Mf3 alveolus is a little more squared than the Mf2. The
Mf4 alveolus is mediolaterally narrower than the preceding alveolus and the lingual side is more anteroposteriorly compressed than the labial side, giving it a subtriangular appearance with unequal sides. The posterior border of the Mf4 alveolus also has a protrusion into the alveolar space. MHD 412 retains most of the anterior-most border of the maxilla that would have articulated with the absent premaxillae. This border is U-shaped, although there may have been an anteriorly projecting spicule of bone from near the midline. The anterior palatine foramina are located at the anterior Mf1 alveolar margin in MHD 347, unequally posterior and anterior to the Mf1 alveolus in MHD 351, and in the diastema region of MHD 412.

The vomer is rather well preserved in MHD 347 and 412, and in anterior view it is T-shaped. From the dorsal part of the bone, the processes extend laterally to the ventrally directed nasomaxillary crests and then curve ventrally to run along the medial margin of the nasomaxillary crests. The ventral part of the vomer reaches to the maxillary crest that dorsally projects from the hard palate.

Mandibulae (MHD 406, 408): Like the holotype, neither mandible is complete, but each specimen retains the teeth from the left molariform series; caniniforms are absent (Fig. 11I-L). Of the measurements obtained, the most significant differences between the two species are the length of the diastema, total length of the dental series, and width of the mandibular condyle (Tab. 5).

Although there may be dental characters unique to the species of Parocnus from Hispaniola, the rarity of mandibular teeth for $P$. serus currently makes such determinations impossible. However, $P$. dominicanus can be distinguished by the alveolar outlines in dorsal view, where the labial alveolar margin of $\mathrm{mf1}$ bulges past the same margin of $\mathrm{mf}$; these same labial margins in P. serus are in line with one another. Additionally, the alveolae for the lower caniniforms indicate the teeth would be more anteriorly directed in $\mathrm{P}$. dominicanus than those of $P$. serus, which is slightly more laterally projected. Like the upper caniniforms, the lower alveoli are subtriangular and with slight protrusions along the inner surface of each alveolar margin.

The $\mathrm{mf} 1$ tooth is somewhat rectilinear but a protrusion on the anterior side of the alveolus gives the tooth an anterior indentation and groove (Fig. 11J, L). This, along

Figure 11 (opposite page). Paratype crania from La Jeringa and paratype mandibles from Padre Nuestro of Parocnus dominicanus. Crania: MHD 347 in A, dorsal and B, ventral view; MHD 351 in C, dorsal and D, ventral view; MHD 412 in E, dorsal and F, ventral view; MHD 411 in G, dorsal and H, ventral view. Mandibles: MHD 406 in I, left lateral and J, dorsal view; MHD 408 in $\mathrm{K}$, right lateral and $\mathrm{L}$, dorsal views. Abbreviations: Cf/cf, upper caniniform/lower caniniform; cnp, coronoid process; $\mathrm{mc}$, mandibular condyle; Mf/mf, upper molariform/lower molariform; pf, palatine foramina; pop, postorbital process; ps, palatine sulci. Diagnostic characters: 1 , union of temporal lines into sagittal crest occurs anterior to the roots of the squamosal processes of the temporal; 2, medioventral bulging of the cf1 roots creates a U-shape with posterior symphysis; 3, labial margin of $\mathrm{mf} 1$ laterally bulges past the $\mathrm{mf} 2$ and $\mathrm{mf} 3$ labial margins. Scale bars equal to $5 \mathrm{~cm}$. 


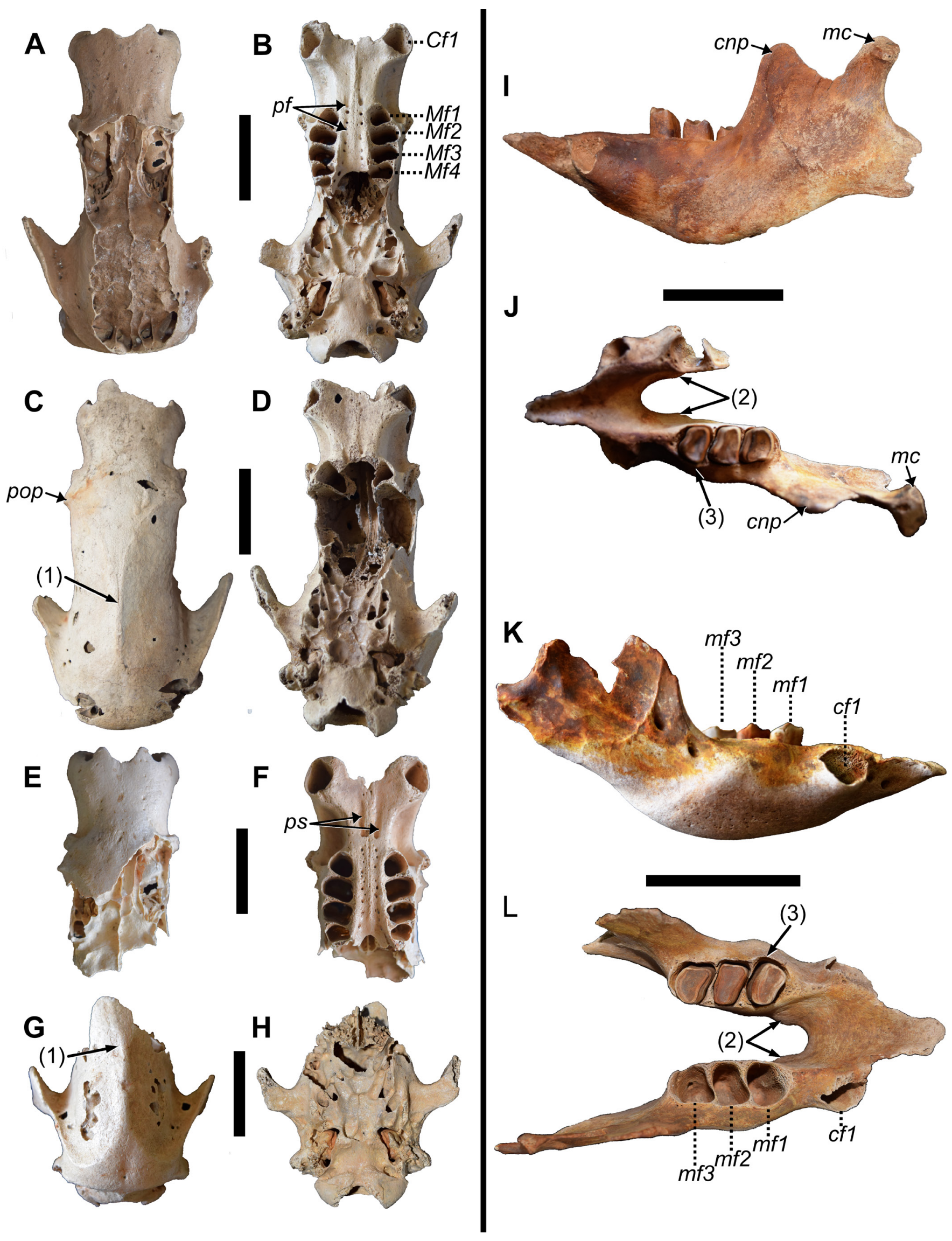


Table 5. Mandibulae measurement (in millimeters) of Parocnus dominicanus and $P$. serus.

\begin{tabular}{|c|c|c|c|c|}
\hline & \multicolumn{2}{|c|}{ P. dominicanus $\left(\mathrm{n}=13^{*}\right)$} & \multicolumn{2}{|c|}{ P. serus $(\mathrm{n}=2)$} \\
\hline & Mean & St Dev & Mean & St Dev \\
\hline Predental spout length & 43.5 & 6.6 & 52.4 & -- \\
\hline Predental spout width & 19.5 & 2.6 & 18.6 & -- \\
\hline Length of symphysis to level of canines (excluding projection) & 29.9 & 2.7 & 51.6 & -- \\
\hline Toothrow length & 60.7 & 8.2 & 76.9 & -- \\
\hline cf1 alveolar width & 12.6 & 2.2 & 13.0 & -- \\
\hline cf1 alveolar length & 12.6 & 1.5 & 11.7 & -- \\
\hline Diastema length (cf1-mf1) & 15.6 & 2.1 & 26.0 & -- \\
\hline Molariform toothrow length & 36.9 & 1.9 & 40.9 & -- \\
\hline mf1 alveolar width & 14.5 & 1.3 & 15.0 & -- \\
\hline mf1 alveolar length & 13.1 & 0.3 & 10.2 & -- \\
\hline mf2 alveolar width & 15.1 & 1.5 & 14.8 & -- \\
\hline mf2 alveolar length & 11.5 & 1.5 & 10.5 & -- \\
\hline mf3 alveolar width & 13.0 & 1.6 & 13.7 & -- \\
\hline mf3 alveolar length & 12.6 & 1.3 & 11.9 & -- \\
\hline Breadth of mandible across canines & 49.5 & 3.3 & 57.7 & -- \\
\hline Width between C1's & 23.3 & 2.4 & 35.2 & -- \\
\hline Width of mandible at mf1 & 20.7 & 1.7 & 23.0 & -- \\
\hline Width of mandible at $\mathrm{mf3}$ & 25.8 & 10.0 & 25.9 & -- \\
\hline Depth at $\mathrm{mf} 2$ & 36.0 & 2.7 & 41.8 & -- \\
\hline Ramus height from base to notch & 37.9 & 3.5 & 54.0 & -- \\
\hline Ramus height from base to condyle & 51.1 & 0.0 & 57.6 & -- \\
\hline
\end{tabular}

with the morphology of the posterior margin, gives the tooth a mediolaterally curved appearance. The $\mathrm{mf} 2$ tooth is more rectilinear but the lingual side is anteroposteriorly compressed compared to the longer labial side. Individual variation between specimens produces an indentation and groove on the anterior side of this tooth in MHD 406 that is not as evident in MHD 408. The cusps for the first two molariforms are most prominent at the anterolingual and posterolabial corners of the teeth, such that the trough is oriented between them along an anterolabial to posterolingual axis. In $\mathrm{mf3}$, the labial and lingual sides are higher than the anterior and posterior sides, creating a shallow and uniform trough. The mf3 tooth morphology is subquandrangular with a pronounced indentation along the labial side, which with a shallow indentation of the anterior side forms a small lobe at the anterolabial corner. The posterior margin is convex and curves strongly towards the lingual side such that a distinct posterolingual corner to the tooth is absent.

Predental spouts taper anteriorly but do not form a point (Fig. 11J, L). The lateral margins in both specimens are abraded and incompletely preserved but are clearly raised to form a shallow trough for the spout. The length from the mental symphysis is about the same as the dorsoventral extent of the symphysis. Mental foramina are present underneath and lateral to the spout, with the standard sloth pattern of at least one main foramen, which may or may not be accompanied by a second smaller foramen per side. MHD 406 preserves the nearly complete coronoid process and mandibular condyle on the left side (Fig. 11I). With the toothrow level in lateral view, the mandibular condyle sits more dorsal than does the coronoid process. The mandibular condyle is transversely wide, with a greater lateral extent from the attachment to the mandibular neck. Despite the seemingly flat nature of the glenoid fossa in the cranium, the mandibular condyle is arched with the greatest dorsal extent in the middle and tapering ventrally to the sides.

Atlas, C1 (MHD 836, 837): The ventral and dorsal arches each lack tubercles for muscle tendon attachment (Fig. 12B, C, E, F), which may be related to their smaller size than P. serus. The cranial articular facets for the occipital condyles are not very distinct. When viewed dorsally, these facets in P. serus project cranially from the dorsal arch and the cranial margins of the alar wings. Ventrally, there is not the same separation from the alar wings but there is the distinct projection from the ventral arch.

Although the referred specimens bear damage to the alar wings, there is enough preserved to gain a complete picture of their morphology. The alar wings in P. serus and 


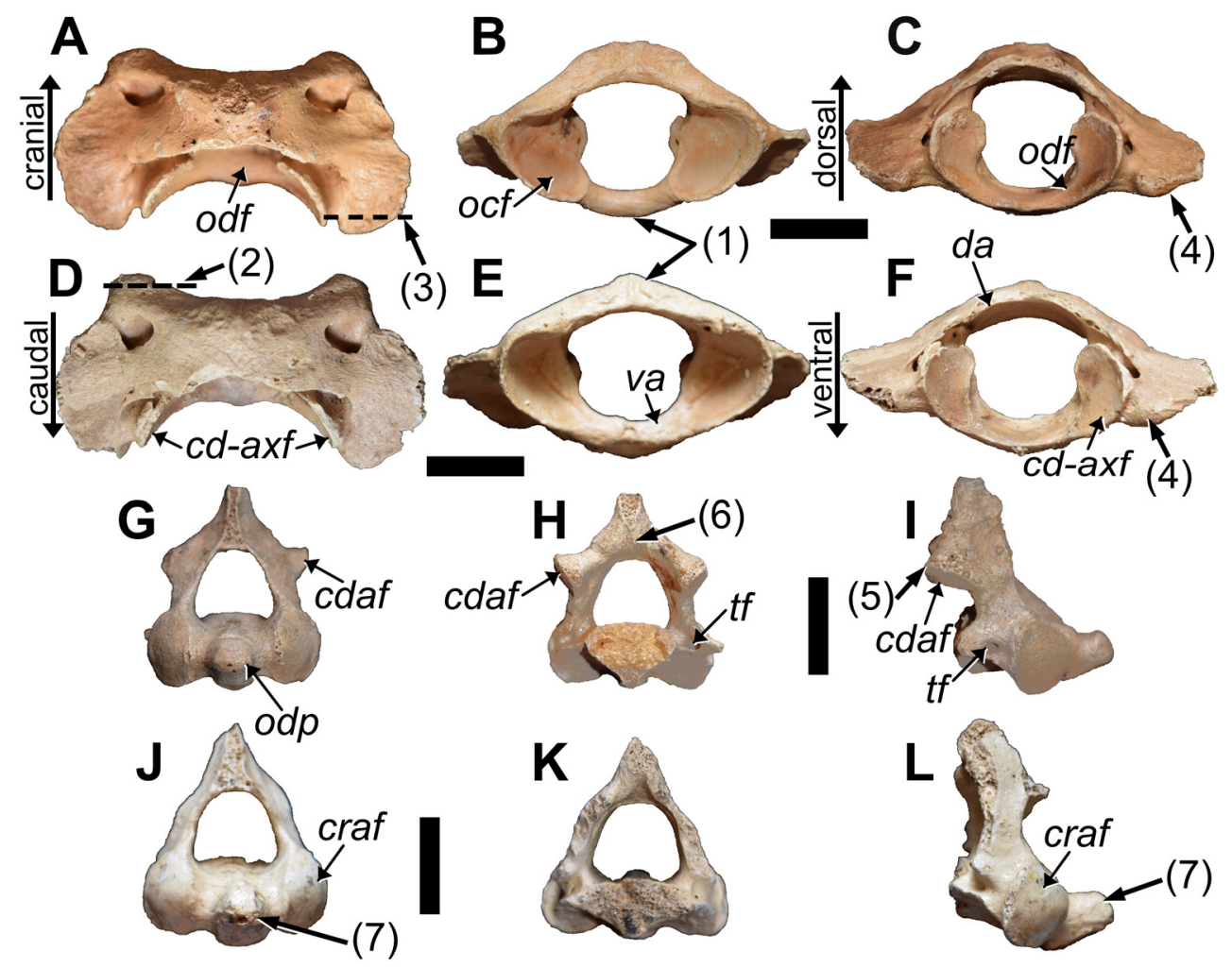

Figure 12. Paratype atlas (C1) and axis (C2) vertebrae from La Jeringa of Parocnus dominicanus. Atlas: MHD 836 in A, dorsal, B, cranial, and C, caudal views; MHD 837 in D, dorsal, E, cranial, and F, caudal views. Axis: MHD 909 in G, cranial, H, caudal, and I, right lateral views; MHD 910 in J, cranial, K, caudal, and L, right lateral views. Abbreviations: cdaf, caudal facet; cd-axf, caudal/axial facet; craf, cranial articular facet; da, dorsal arch; ocf, occipital fossa; odf, odontoid facet; odp, odontoid process; tf, transverse foramen; va, ventral arch. Diagnostic characters: 1, C1 dorsal and ventral arch tubercles absent or weak; 2 , occipital condyles of $\mathrm{C} 1$ with minimal anterior projection from the ala and dorsal arch; 3 , minimal extension of the caudal alar wing margins and a small separation from the axial/caudal articular facets; 4, caudal alar tubercles are medially positioned; 5, C2 caudal articular facets with minimal caudal extension from the dorsal spinous process; 6 , absent or weak depression at the caudal base of the $\mathrm{C} 2$ spinous process; 7, odontoid process rounded and blunt. Scale bars equal to $2 \mathrm{~cm}$.

P. dominicanus are rounded and exhibit a dorsoventral angle from the cranial to the caudal margin. The caudal margin extends beyond the caudal facets to the axis vertebra in $P$. serus but ends at nearly the same transverse plane in $P$. dominicanus (Fig. 12A). This is also evident in caudal view where the caudal alar tubercle sits more medial towards the caudal articular facet in $P$. dominicanus (Fig. 12F), while it is more lateral in $P$. serus. Neither species exhibits connections between the caudal edge of the dorsal arch and the dorsal edge of the caudal articular facets as exhibited by Acratocnus, as well as by some mylodontids (McAfee 2016) and likely other sloth taxa.

Axis, C2 (MHD 909, 910): None of the specimens assigned to $P$. serus or $P$. dominicanus are complete, with most of the damage related to the spinous process, the transverse process and foramina, and caudal portions of the centrum (Fig. 12G-L). The only noticeable difference lies in the absence of a depression at the base of the spinous process in caudal view in $P$. dominicanus, whereas there is a distinct excavation in $P$. serus.
The odontoid process is rounded and blunt, anterodorsally angled, and bears a facet on the ventral surface for articulation with the inner surface of the ventral arch of $\mathrm{C} 1$. The round, blunt shape contrasts with that of P. serus (MHD 894), where the cranial tip is dorsoventrally flattened and more pointed. The caudal articular processes, retained only in MHD 909 (Fig. 12I), are not as prominent nor as caudally extended as those seen in $P$. serus.

Radii (MHD 349, 521, 526): The radial head is more ovate than circular, and the overall rim is of equal height all the way around the shallow articular depression, giving it a flat appearance. In P. serus, the height of the rims is unequal, with the posterior side that bears the ulnar articulation being taller and giving the proximal end an anteroposteriorly angled appearance; similar morphology is also seen in $P$. browni (Fischer 1971). The greater posterior height in P. serus also corresponds with a taller proximal ulnar articular surface than that of $P$. dominicanus. This also creates a defined indentation for a neck-like region in $P$. serus, whereas there is no obvious neck in P. dominicanus (Fig. 13). 


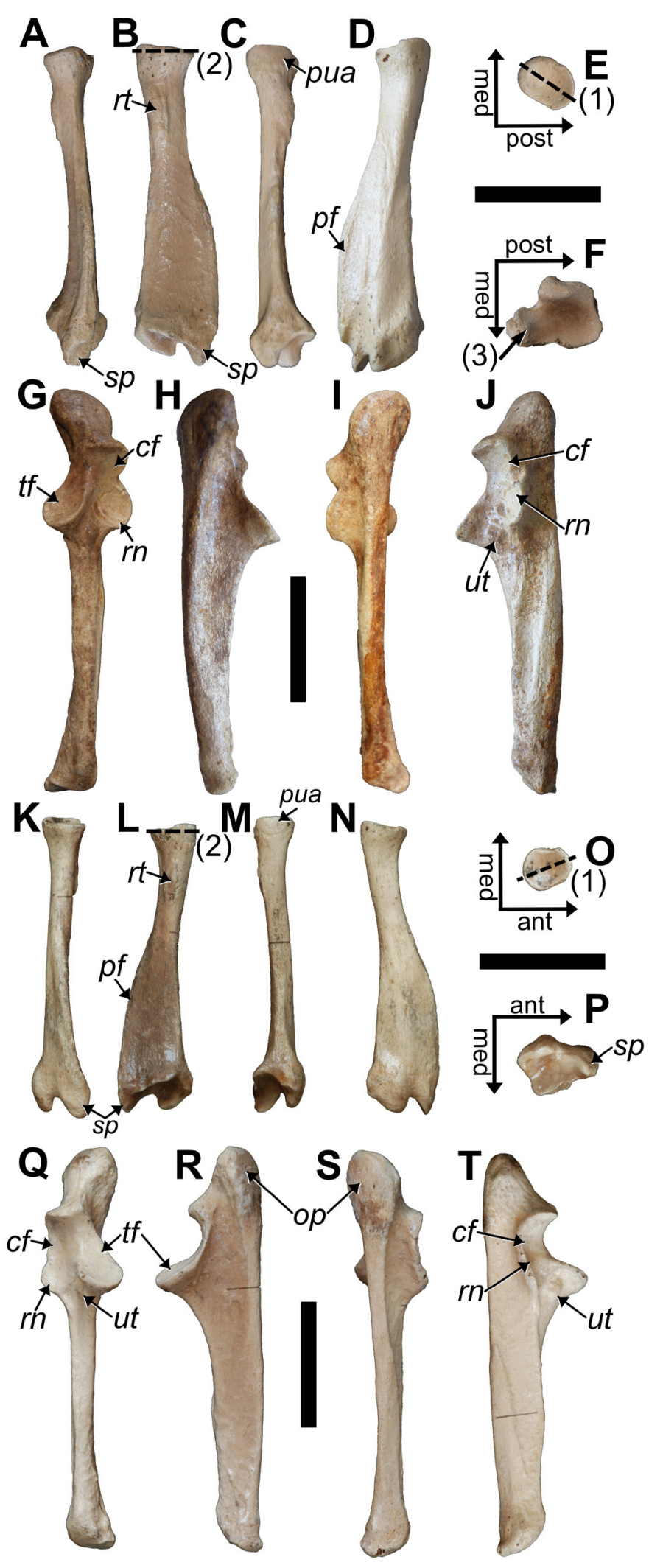

The diaphysis is slightly bowed, in a manner more akin to that seen in Neocnus and Megalocnus, but the distal expansion of the pronator flange is more pronounced than in Neocnus and P. browni, and it begins more distally than in Megalocnus. The radial tuberosity is near to the posterior border but occupies a position on the medial surface where it presents an ovate region, elongated in the proximodistal plane. The medial surface is concave and slightly rugose, while the lateral surface is convex, smooth, and mediolaterally separated by a small ridge. The posterior (inner) surface of the diaphysis is rugose and distally broadens into a triangular shape. The anterior (external) side bears the pronator flange, which sometimes bears a distinct ridge. The distal articular surface can be divided into anterior and posterior surfaces. The anterior surface occurs along the inside of the radial styloid process and is convex. In MHD 349 and 526 the surface has a squared appearance in distal view (Fig. 13F), but in MHD 521 the anterior portion is rounded and slightly tapered (Fig. 13P). The surface does not appear to be heavily involved in articulation with the scaphoid and serves more as a lateral boundary to carpal abduction. The posterior surface is concave and deepened by a bony ridge projected from the lateral surface. The anterior point of this ridge joins with the proximodistal ridge along the lateral radial surface, and overall serves as a backstop that limits the degree of carpal extension by the scaphoid. The medial margin of the distal articular surface exhibits a slight indentation at the boundary between the posterior and anterior portions.

Compared to other limb elements, the radii of $P$. dominicanus are significantly shorter than those of P. serus (Tab. 6). The percent difference in length for all the other limb elements averages at $14.3 \%(12.1-17.5)$, while that of the radius is $23.9 \%$. Why this greater difference in length between the species occurs is uncertain, although it may relate to sample size.

Ulnae (MHD 224, 225, 348, 512, 515): Similar to the other Parocnus species, the ulnae have a pronounced olecranon process, and their diaphysis is rectangular, anteroposteriorly unbowed, and slightly tapered at the distal end (Fig. 13). The olecranon is not as robust as in Megalocnus but it exhibits a greater medial inclination than seen in Megalocnus, which is also true for P. serus. At the base of the olecranon in P. serus, just above the trochlear notch, is a distinct tubercle that is not found in P. dominic-

Figure 13. Paratype radii and ulnae of Parocnus dominicanus from La Jeringa and Padre Nuestro. Radii: MHD 349 (left) and MHD 521 (right) in A \& K, anterior, B \& L, medial, C \& M, posterior, D \& N, lateral, E \& O, proximal, and F \& P, distal views. Ulnae: MHD 225 (left) and MHD 348 (right) in G \& Q, anterior, H \& R, medial, I \& S, posterior, J \& T, lateral views. Abbreviations: cf, capitular facet; op, olecranon process; pua, proximal ulnar articulation; rn, radial notch; rt, radial tubercle; sp, styloid process; tf, trochlear facet; ut, ulnar tuberosity. Diagnostic characters: 1, long axis of the radial head oriented anteromedial to posterolateral; 2, anterior and posterior radial head margins less angled and closer to horizontal; 3, scaphoid facet along the styloid process is uniformly wide and untapered. Scale bars equal to $5 \mathrm{~cm}$. 
McAfee et al. - New species of the ground sloth Parocnus

Table 6. Forearm bone measurements (in millimeters) for Parocnus dominicanus and $P$. serus.

\begin{tabular}{|c|c|c|c|c|}
\hline \multirow[b]{2}{*}{ Radius } & \multicolumn{2}{|c|}{ P. dominicanus $(\mathrm{n}=7)$} & \multicolumn{2}{|c|}{$P$ serus $(\mathrm{n}=4)$} \\
\hline & Mean & St.Dev & Mean & St. Dev \\
\hline Total length & 120.1 & \pm 5.4 & 157.9 & \pm 2.6 \\
\hline Length of distal articular surface & 28.8 & \pm 1.8 & 35.0 & \pm 1.8 \\
\hline Length of radial tuberosity & 17.3 & \pm 1.7 & 22.4 & \pm 2.9 \\
\hline Width of radial tuberosity & 7.3 & \pm 1.2 & 9.8 & \pm 1.4 \\
\hline ML head width & 20.6 & \pm 2.2 & 24.9 & \pm 0.3 \\
\hline \multirow[t]{2}{*}{ AP head width } & 16.8 & \pm 2.0 & 21.6 & \pm 0.5 \\
\hline & \multicolumn{2}{|c|}{ P. dominicanus $(\mathrm{n}=12)$} & \multicolumn{2}{|c|}{ P. serus $(\mathrm{n}=3)$} \\
\hline Ulna & Mean & St.Dev & Mean & St. Dev \\
\hline Total Length & 151.0 & \pm 6.6 & 177.0 & \pm 14.7 \\
\hline Length: superior point of trochlea to distal end & 130.8 & \pm 4.1 & 152.6 & \pm 9.1 \\
\hline Length: between distal trochlea $\&$ radial notch to distal end & 111.9 & \pm 3.4 & 131.9 & \pm 19.0 \\
\hline Maximum width of olecranon (posterior) & 24.0 & \pm 2.0 & 28.0 & \pm 2.2 \\
\hline Width of proximal radial articular notch & 17.9 & \pm 1.3 & 24.9 & \pm 4.4 \\
\hline Maximum width of proximal articular surface (from distal area) & 32.4 & \pm 2.9 & 37.5 & \pm 1.4 \\
\hline AP width of distal ulnar articular surface & 12.4 & \pm 1.0 & 14.0 & \pm 1.7 \\
\hline AP medial width of distal ulnar articular surface & 15.1 & \pm 1.5 & 15.7 & \pm 0.2 \\
\hline AP depth at distal proximal articular surface (trochlea) & 39.4 & \pm 1.3 & 47.7 & \pm 3.5 \\
\hline AP depth at proximal point of prox articular surface & 29.5 & \pm 1.5 & 37.9 & \pm 2.2 \\
\hline
\end{tabular}

anus. Other than size, this constitutes the only noteworthy difference between the Hispaniolan species of Parocnus.

The trochlear surface is shallow and is distinctly separate from the capitular and radial notch surfaces. The capitular and radial surfaces are also rather flat. The lateral border between the two facets is variable as sometimes there is a notch (e.g., MHD 225), similar to that of Megalocnus, but in other specimens they are connected by a bony ridge. The radial notch is rounded and closer to the trochlea than in Megalocnus. The ulnar tuberosity is weakly developed and variable in its presentation and location distal to and between the trochlea and radial notch.

The diaphysis and distal end are slightly mediolaterally bowed such that the concave surface is medially directed. A ridge extends from the distolateral end of the radial notch to the anterior surface and continues to the distal end. A parallel ridge occurs on the lateral surface from near the posterior margin and towards the distal end, but it is not as distinct. The distal articular surface is either circular or D-shaped.

Scaphoids (MHD 838A, 839): While approximately the size of the same element in Acratocnus, the specimens recovered from La Jeringa (Fig. 14A-F) correspond to the morphology Fischer (1971) described for P. browni. The proximal articular surface of the radius is equally tall and broad, and is divided into a convex medial portion and a concave lateral portion, which compliments the distal articular surface of the radius. In P. serus, the surface is not as equal in its presentation, with medial and lateral margins angled. The proximal articular surface bears a small notch on the lateral side, just below the distopalmar projection in MHD 838A but it is not present in MHD 839. The distopalmar projection extends at about $45^{\circ}$ and at its distolateral tip bears a small, rounded facet for articulation with the trapezium/Mc1. Because neither the trapezium nor $\mathrm{Mc1}$ have been recovered at any sites to date, it is unclear if they exhibited a fusion that is common in other late Pleistocene sloths (Stock 1925), and hence the uncertainty as to the specific articulation.

The dorsal surface has a central concavity that is emphasized by a further dorsal extension from the distal margin. The extension corresponds to part of the articular facet for the magnum on the distal side, but on the dorsal side, it serves as a bony stop for extension of the carpus against the radius. The distal surface is divided into three facets. The central facet for the magnum is the most obvious; the other two are best viewed in either medial or lateral view. The magnum surface occupies the dorsal half of the distal surface and is somewhat triangular in appearance. However, in $P$. serus there is small palmar portion separated from the larger dorsal part. Laterally and at its dorsal end, the magnum facet shares a sharp, $90^{\circ}$ ridge with a facet for the trapezoid, which is concave towards the palmar end. As the facets 

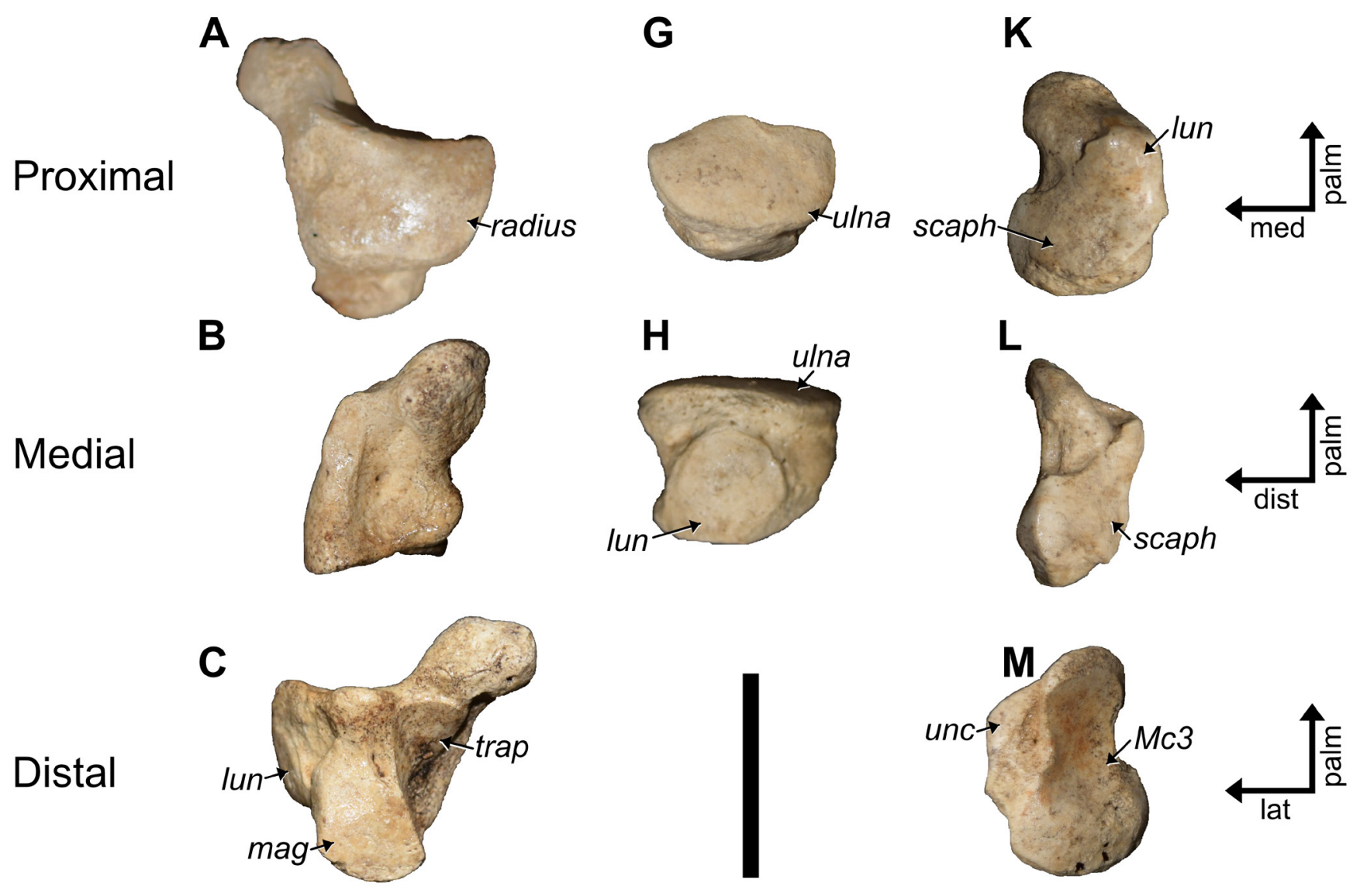

Lateral

D

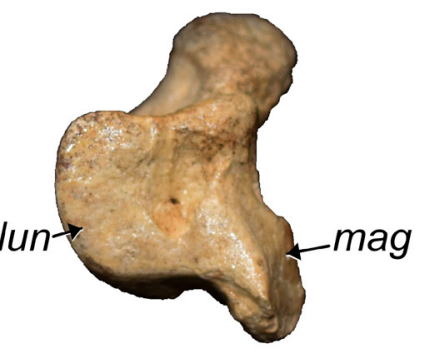

E

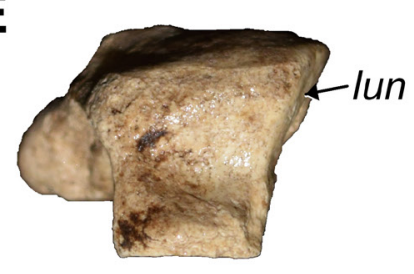

$\mathbf{F}$

\section{Palmar}

Dorsal
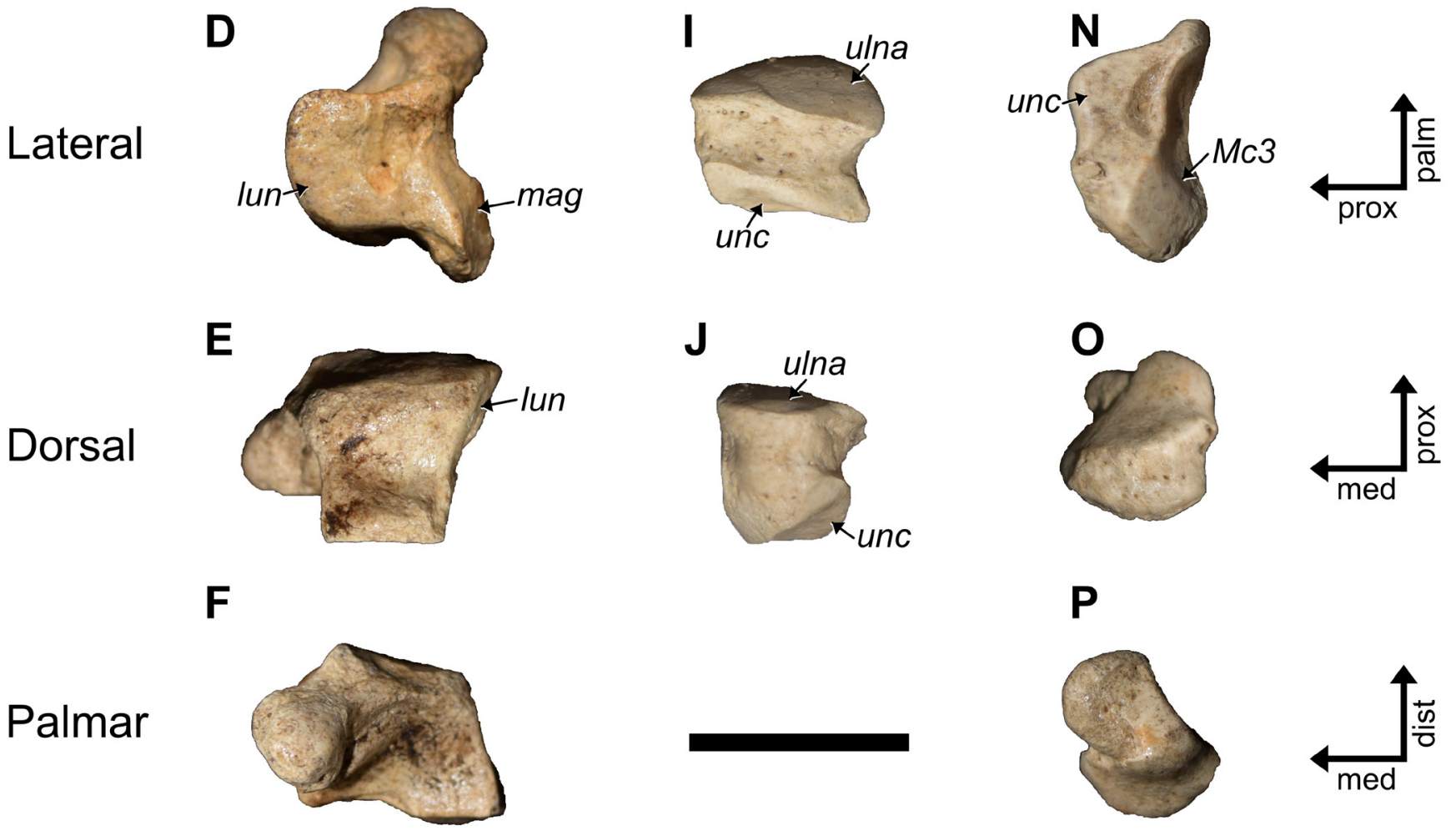
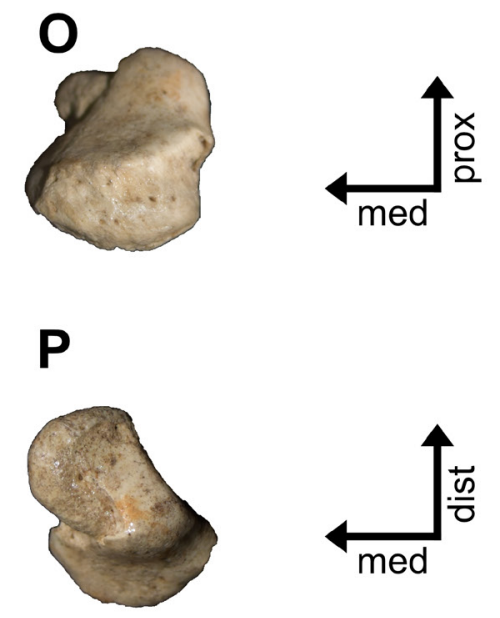

FIGURE 14. Paratype carpals of Parocnus dominicanus from La Jeringa. Image views indicated on the left for A-F, scaphoid MHD 838A, G-J, cuneiform MHD 838C, and K-P, magnum MHD 838B. Abbreviations: lun, facet to the lunate; mag, facet to the magnum; Mc3, facet to Mc3; radius, radial facet; scaph, facet to the scaphoid; trap, facet to the trapezoid; ulna, ulnar facet; unc, facet to the unciform. Scale bars equal to $2 \mathrm{~cm}$. 
begin to separate towards the middle of the distal side, the trapezoid trends towards the medial side and its shared ridge with the facet for the lunate. Palmar to the magnum surface there is a tubercle-like protrusion in MHD 838A, which is not present in MHD 839.

Cuneiform (MHD 838C): Proximal surface is broader, more rounded, and lacks the 'sole-shape' (sohlenförmige) as described for P. browni (Fischer 1971), but it does maintain the dorsopalmar axis (Fig. 14G-J). The palmar end of the surface occupies a little more of the lateral side and is pointed. This pointedness is reflected in palmar view for both the proximal and distal articular facets, which are separated by a trough, and the pointed palmar end of the distal unciform facet is situated more medial than the proximal radial facet. There are two small facets abutting the proximal and distal sides that may correspond to articulation with the pisiform, but there is otherwise no specific articular facet for that carpal bone.

In medial view, the lunate facet is ovate, separate from the proximal surface, and its distal margin abuts with the facet for the unciform. Laterally, there is a small extension of the unciform facet towards the dorsal end, while at the palmar end there is a small, elongated facet that abuts the uniform facet and may represent articulation for the Mc5. Distally, the unciform facet is somewhat triangular, lightly concave, and the long axis is obliquely oriented in a mediolateral direction.

Magnum (MHD 838B): The element is overall proximodistally compressed and dorsopalmarly elongated
(Fig. 14K-P). The proximal side is strongly convex and the articular surface conforms to articulations of the lunate, scaphoid, and trapezoid. The facet is narrow and laterally situated at the palmar end and articulates only with the lunate. At the apex of the convexity, the surface medially widens. The apical portion of the convexity corresponds to the lunate, but dorsally becomes slightly concave for the scaphoid. A small section at the dorsomedial edge is the trapezoid surface, which is separated from the tuberous proximal end of the bone by a shallow sulcus. The height of the proximal convexity and the sulcus along the medial edge are clearly seen in medial view.

The lateral surface bears articular facets for the unciform, which follows the contour of the convexity for the lunate articular surface. An excavation along the distal margin separates the palmar and dorsal parts of the unciform arch. In distal view, the Mc3 facet is concave, and the palmar portion is narrower than the dorsal. The narrowing can be attributed to the sulcus on the medial side and the excavation on the lateral.

Mc3 (MHD 838D, 840, 841): As in most sloths, the Mc3 is nearly as long as it is wide at its proximal end (Tab. 7). Proximally, a long lateral projection extends towards Mc4. The Mc2 facet on the medial side is slightly damaged on its dorsal margins but still presents as a rounded tuberosity (Fig. 15A). The facets for the magnum in proximal view are wide dorsally, slightly concave, and angled due to the lateral extension. The lateral and palmar part of the facet is the narrowest part, and there is a small excavation at the

Table 7. Measurements (in millimeters) for the Mc3 and Mc4 of Parocnus dominicanus and P. serus.

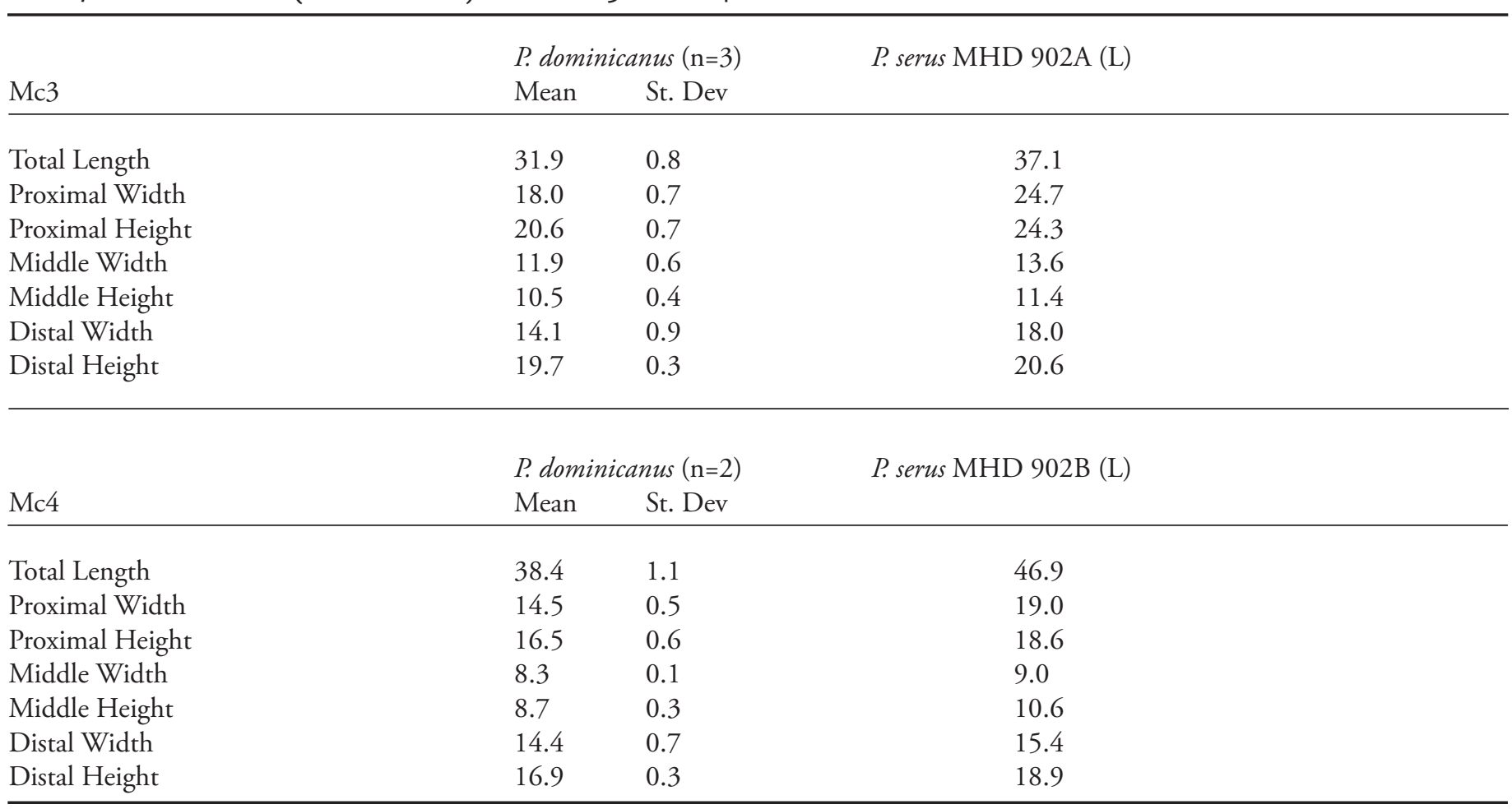




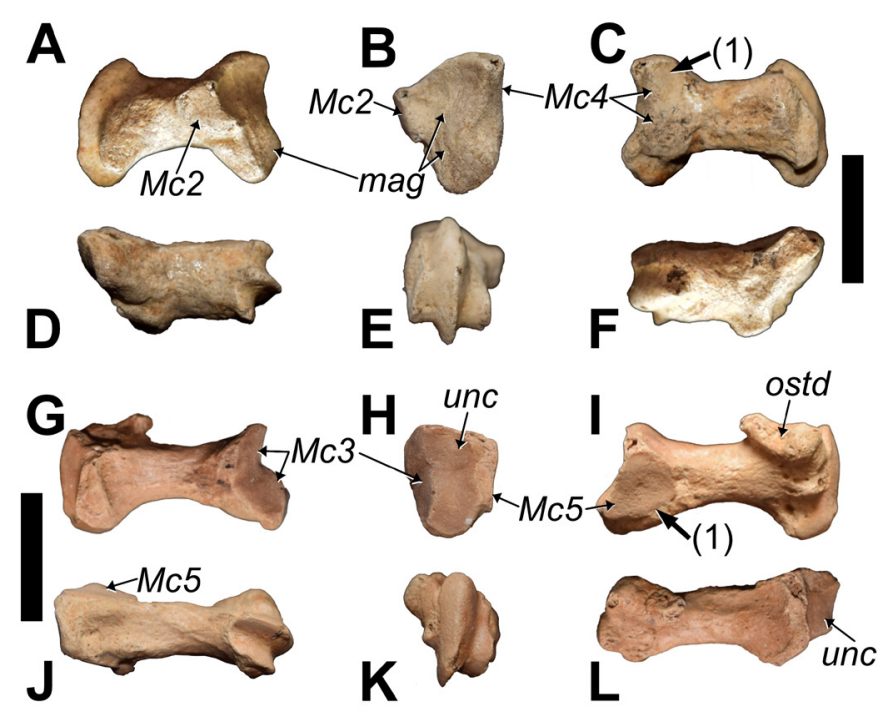

FIGURE 15. Paratype metacarpals of Parocnus domincanus from La Jeringa. Right Mc3 (MHD 840) and right Mc4 (MHD 911) in A \& G, axial/medial, B \& H, proximal, C \& I, abaxial/ lateral, D \& J, palmar, E \& K, distal, and F \& L, dorsal views. Abbreviations: Mc2, facet to Mc2; Mc3, facet to Mc3; Mc4, facet to Mc4; Mc5, facet to Mc5; mag, facet to the magnum; ostd, ossified tendon; unc, facet to the unciform. Diagnostic characters: 1, facet for Mc4 flat; 2, facet for Mc5 positioned closer to the palmar surface and with a short distal extension. Scale bars equal to $2 \mathrm{~cm}$.

middle of the lateral border separating that part of magnum from Mc4. The facets for Mc4 are somewhat triangular and generally flat, in contrast to $P$. serus where it is concave.

The distal carina is thick dorsally and narrow palmarly, which corresponds to widening of the medial and lateral articular surfaces for the proximal phalanx, as well as sesamoids at the most palmar extent (Fig. 15E). The overall carina is angled from dorsolateral to palmaromedial. The most palmar point of the carina lies more distal than the most dorsal point, and also extends palmarly past the diaphysis.

Mc4 (MHD 911, 912): The element is more rectilinear and longer than the Mc3 (Tab. 7). The proximal end exhibits a facet for the unciform that laterally shares a distinct border with the proximolaterally directed Mc5 facet; the Mc3 facet is unconnected (Fig. 15H). The unciform articular facet is dorsally flat and palmarly is slightly convex, which creates a concavity in the middle region. The middle concavity is greater in $P$. serus because the palmar part is more rounded and convex, while the dorsal part is also more concave. The dorsal part of the articulation is also widened laterally, which gives the Mc5 facet a different angle than that of $P$. dominicanus.

Medially, the Mc3 facet is triangular in both $P$. serus and $P$. dominicanus, but in the former it is positioned more dorsally, which creates a small ridge extending distally onto the diaphysis. The position is more palmar in the latter, and there is no proximally extending ridge. At the distal end, MHD 911 has a posterodorsally projecting bony spur (Fig. 15I) that is not seen in MHD 912 or P. serus. It likely represents a piece of ossified tendon. The bony process to which this spur connects represents the medial articulation for the proximal phalanx. It is more developed than in P. serus.

In both species, the vertical carina is relatively flat in side view (although it is slightly convex in P. dominicanus), and the dorsal part is even with the diaphysis while the palmar extends beyond that margin. The palmar margin is proximodistally concave, in contrast to the rather straight margin exhibited by $P$. serus.

Distally, the carina is broader dorsally and sharpens toward the palmar end (Fig. 15K). The medial articulation for the proximal phalanx dorsopalmarly extends to about the middle of the carina, whereas in P. serus it only extends about one third of the length.

Calcaneus (MHD 496): The morphology matches well with the Parocnus holotype specimens Miller (1929) used to establish the new genus, especially in having an elongated tuber calcis with no mediolateral widening of the distal regions (Fig. 16). In P. dominicanus, the flange for tendon passage along the proximolateral side is flattened such that there are grooves for two ankle tendons (Fig. 16A, D), whereas in P. serus, this same region is rounded so that there is only one tendon groove posterior/distal to the flange (Fig. 16F, I). There is a large foramen posterior (distal) to the flange. A foramen is also present in P. serus, but it is much smaller and does not always open on the plantar side. In distal view, the sustentacular and cuboid facets are continuous but can be differentiated by a small ridge (Fig. 16E). Together they are separated from the ectal facet by a sulcus, which is more pronounced in $P$. dominicanus than in P. serus.

Mt2 (MHD 913): The Mt2 of $P$. dominicanus is similar in appearance and nearly equal in size (Tab. 8) to that of P. serus. In dorsal view (Fig. 17F), the former exhibits a constriction of the lateral and medial sides of the diaphysis that is not seen in the latter. The proximal end is triangular with the apex plantar and the base dorsal and bears an indented excavation in the middle of the articulation for the cuneiforms.

The medial Mt1 facet is circular and articulates closely with the receiving facet of the Mt1 (MHD 914). The shape of the same facet in $P$. serus is unclear as the reference specimen (MHD 903) is damaged just dorsal to the facet. Between the distal margin of the Mt 1 facet and a tubercle lateral to the distal carina, there is a clear separation that occurs in $P$. dominicanus and which is not seen in P. serus; a similar separation is also expressed in lateral view. Distally the medial process for the articulation with the proximal phalanx is greatly developed, especially at the dorsal aspect, and obscures all but the very dorsal and plantar parts of 


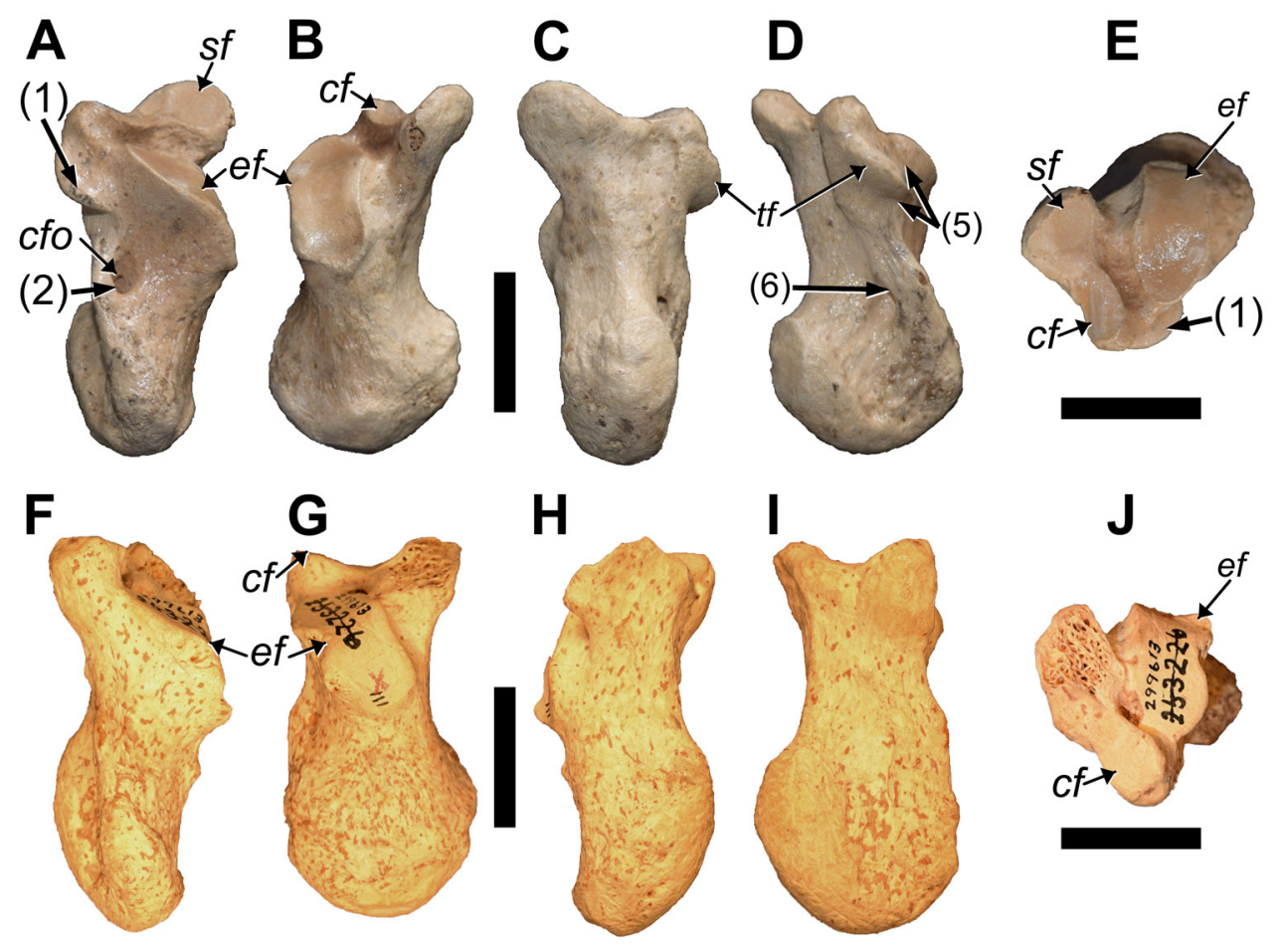

Figure 16. Paratype left calcaneus of Parocnus dominicanus from La Jeringa and comparison to the paratype left calcaneus of Parocnus serus. Left calcaneus (MHD 496) of P. dominicanus in A, lateral, B, dorsal, C, medial, D, plantar, and E, distal views; left calcaneus (USNM PAL 299613) of P. serus in F, lateral, G, dorsal, H, medial, I, plantar, and J, distal views. Abbreviations: cf, cuboid facet; cfo, calcaneal foramen; ef, ectal facet; sf, sustentacular facet; tf, tendon flange. Diagnostic characters: 1, tendon flange flattened and bearing two tendon grooves; 2, calcaneal foramen large. Scale bars equal to $2 \mathrm{~cm}$.

Table 8. Measurements (in millimeters) for the Mt2 and Mt4 of Parocnus dominicanus and P. serus.

\begin{tabular}{lll}
\hline & $\begin{array}{l}\text { P. dominicanus } \\
\text { MHD 913 (R) }\end{array}$ & $\begin{array}{l}\text { P. serus } \\
\text { MHD 903 (L) }\end{array}$ \\
\hline & & \\
Total Length & 23.7 & 25.7 \\
Proximal Width & 14.7 & 14.6 \\
Proximal Height & 16.0 & 15.9 \\
Middle Width & 10.3 & 11.6 \\
Middle Height & 10.2 & 10.6 \\
Distal Width & 13.3 & 13.6 \\
Distal Height & 18.7 & 19.0 \\
& & \\
& P. dominicanus & P. serus \\
Mt4 & MHD 916 (L) & MHD 907A (R) \\
\hline & & \\
Total Length & 36.3 & 40.7 \\
Proximal Width & 12.1 & 13.6 \\
Proximal Height & 20.3 & 21.0 \\
Middle Width & 7.3 & 6.0 \\
Middle Height & 7.0 & 10.1 \\
Distal Width & 9.1 & 10.0 \\
Distal Height & 7.3 & 11.1 \\
& & \\
\hline
\end{tabular}

the carina. The same process is poorly developed in P. serus, although the most developed portion is towards the palmar margin; the carina is fully visible.

Laterally, the Mt3 facet is dorsoplantarly elongate and extends the entire height of the bone (Fig. 17C), whereas in P. serus it is restricted from the dorsal margin to about half the total height. Distally, the process for the lateral articulation with the proximal phalanx is not well-developed and much of the carina is visible. In P. serus the process is well-developed and the carina is obscured.

Distally, the carina is slightly angled from being fully vertical, as it is in P. serus, and is broader or rounder dorsally than plantarly in its width (Fig. 17E). The medial articulations are equivalent in presentation between the two species, but the lateral is more developed and dorsopalmarly elongate in $P$. dominicanus.

Mt4 (MHD 916): The Mt4 is distally wide, proximally tapered, and is slightly smaller than in P. serus (Tab. 8). The diaphysis is narrower than in $P$. serus and exhibits sharp ridges of the dorsal and plantar surfaces.

In proximal view the cuboid facet is dorsopalmarly rectilinear (Fig. 17H) but is teardrop shaped in P. serus, with the dorsal part being the site of the narrowing. The Mt3 is medially facing; as a result, it is only partly visible in 


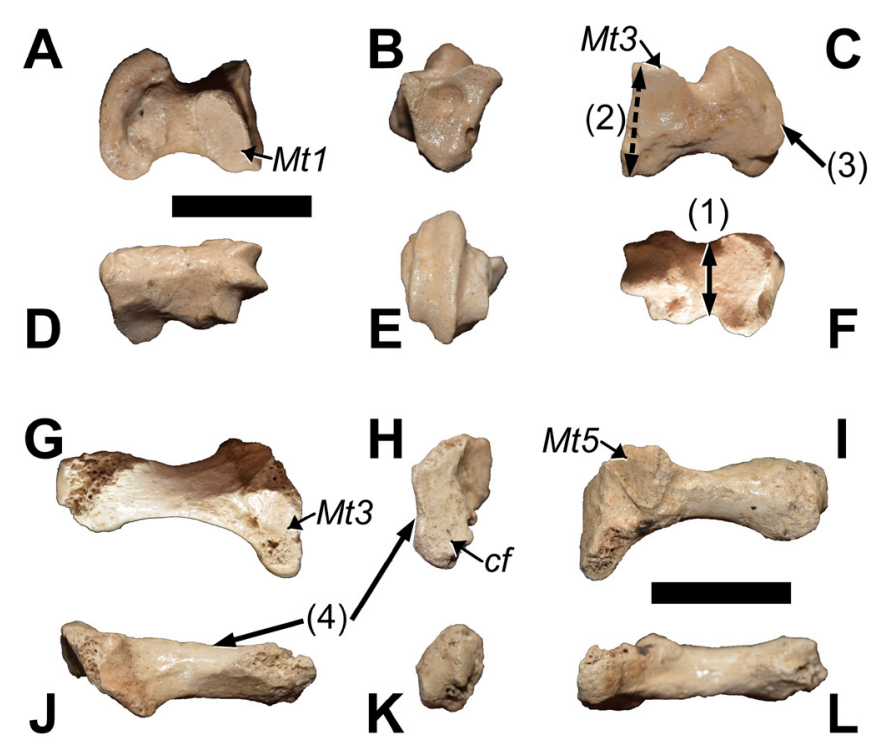

FIGURE 17. Paratype left metatarsals of Parocnus dominicanus from La Jeringa. Right Mt2 (MHD 913) A, axial/medial, $B$, proximal, C, abaxial/lateral, D, dorsal, E, distal, and D, plantar views; Left Mt3 (MHD 911) in G, axial/medial, $H$, proximal, I, abaxial/lateral, J, dorsal, I, distal, and K, plantar views. Abbreviations: cf, cuboid facet; Mt1, facet to Mt1; tf, tendon flange to Mt1; Mt3, facet to Mt3; Mt5, facet to Mt5. Diagnostic characters: 1, Mt2 diaphysis constricted in dorsal view; 2. facet for Mt3 extends to the dorsal and bearing two tendon grooves; 3 , carina obscured in lateral view; 4, Mt4 diaphysis with sharp margins and the cuboid facet. Scale bars equal to $2 \mathrm{~cm}$.

proximal view. In $P$. serus, it faces more proximally and is positioned dorsal to the cuboid facet; as a result, it is fully visible. The orientation and offset of the facets are evident in dorsal view because they produce an indentation and medial 'hook,' in P. serus that is not seen in P. dominicanus. Laterally, the articulation for Mt5 is unclear due to damage in the specimen but is likely triangular (Fig. 17I). This facet is very small and triangular in $P$. serus and is clearly separate from the proximal facets; this aspect of $\mathrm{Mt} 5$ in $P$. dominicanus cannot be determined at this time.

The distal carina is small in both species, but the full characteristics of MHD 916 are unclear as the palmar part is broken. There is no lateral articulation for the proximal phalanx in either species, but the medial articulation is present and is plantarly positioned.

\section{DISCUSSION}

Difference in size is one of the primary separators of Parocnus domincanus and P. serus, with many of the measurements consisting of non-overlapping value ranges (Tabs. $1-8)$. The differences in limb bone lengths vary between $12 \%$ and $23 \%$, with an average difference of $15.2 \%$; width/ depth dimensions are of equal ranges. While cranial and mandibular elements are not as complete and numerous as the limbs, both exhibit similar size differences. Coefficients of variance $(\mathrm{CV})$ calculated for the total element length from the Parocnus specimens showed that when all specimens were combined the values were higher than when separated into the new species groups (see McAfee and Beery 2021). Most of the combined CV values are in the $8-9 \%$ range, which is above the range of variance that can be expected for a singular species (Kurtén 1953; Simpson et al. 1960; Yablokov 1974; Prothero and Raymond 2008). In addition to occupying largely distinct size ranges, $P$. dominicanus and $P$. serus also exhibit a host of qualitative character differences for most of the elements. A number of those can be considered size-related, such as the relative size of a feature (e.g., a tubercle). In some cases, despite being smaller than $P$. serus, $P$. dominicanus exhibits features that are more prominent. Examples include the labial outline of the mandibular molariforms such that $\mathrm{mf1}$ alveoli extends beyond the $\mathrm{mf} 2$ alveoli, the fibular lateral malleolus with a prominent flange and tendon groove, and the calcaneal tendon flange and foramen being greater in relative size.

The two species appear to be geographically isolated from each other, as specimens conforming to the size and morphology of $P$. dominicanus have only been found from Padre Nuestro and La Jeringa, and both localities are devoid of any specimens that could be attributed to P. serus. McAfee and Beery (2021) outlined differences in upper limb morphology and demonstrated that size differences correlated with geographic origin and were not attributable to sexual dimorphism. Based on museum collection data, the nearest occurrences of $P$. serus are $46.7 \mathrm{~km}$ to the northeast and $92.2 \mathrm{~km}$ to the west. There are no evident geographical barriers between those sites. Although P. serus has most frequently been recovered from lowland regions (McAfee and Beery 2021), there have been remains found at sites above $1500 \mathrm{~m}$ (Trouing de la Scierie, Trujin Bridge; MacPhee et al. 2000), suggesting that topographically variable landscapes would not have prevented $P$. serus from reaching the Nacional Parque del Este region.

It is possible that this apparent isolation is an artefact of temporal separation between the species. Many sites in the Dominican Republic where paleontological material has been recovered are underwater making radiocarbon dating impossible as organic material leaches out of the specimens relatively rapidly; additionally, the failure of radiocarbon dating may also indicate that the specimens are very old. Because of these issues with dating, it is difficult to determine the temporal span of the accumulated material in the caves and if $P$. serus and $P$. dominicanus co-existed or were separated temporally.

Without known dates it cannot be ascertained what interactions these sloths may have had with humans on 
McAfee et al. - New species of the ground sloth Parocnus

Hispaniola and how human arrival around 5000-6000 thousand years ago (Cooke et al. 2017) might have impacted their populations and evolution. We do know, though, that at least some large species of sloths survived on the Haitian Tiburon Peninsula until after the arrival of humans on the island (Steadman et al. 2005). The discovery of new cave sites and other fossil finds should produce additional evidence on the potential geographic and temporal isolation of $P$. dominicanus.

Evidence for sexual dimorphism in various ground sloths has steadily increased (Cartelle and Bohórquez 1982; Cartelle and De Iuliis 2006; McDonald 2006; Miño-Boilini and Zurita 2015; Boscaini et al. 2019; Cartelle et al. 2019) and has long been thought to account for the wide variability seen in the Caribbean sloths (Matthew and Paula Couto 1959; Taboada et al. 2007). The type locality of Padre Nuestro and nearby La Jeringa each contain the remains of multiple Parocnus individuals (MNI = 5 PN, $12 \mathrm{LJ})$. McAfee and Beery (2021) demonstrated that specimens for each sloth taxon at each locality exhibit a size dimorphism, which they referred to as long and short morphs. An argument could be made that $P$. dominicanus is a small sexual morph of $P$. serus, but that seems unlikely given that the known $P$. dominicanus localities have multiple individuals, making it unlikely that only smallest $P$. serus individuals were fossilized. The overall pattern seen is an absence of $P$. serus in the $P$. dominicanus type localities, and an absence of $P$. dominicanus in the $P$. serus dominated localities. The conclusion from the evidence at each locality is that the two are separately occurring species and that some level of sexual dimorphism is common within the Parocnus genus on Hispaniola. The limited data from Cuba suggest $P$. browni could also exhibit a similar sexual dimorphism pattern (Matthew and Paula Couto 1959; Fischer 1971; Taboada et al. 2007), but more data are required.

There is some evidence, though inconclusive due to poor temporal control, that humans and $P$. dominicanus may have co-occurred. Several archaeological finds have been recovered from Padre Nuestro (Beeker et al. 2002; Keller 2009). Archaeological explorations of the site were first conducted by the Indiana University Office of Underwater Science and Academic Diving Program. Alongside Taino cultural material, the archaeologists recovered multiple individuals of Acratocnus ye and a juvenile skeleton of Parocnus (Keller 2009), which the authors have not been able to examine for inclusion in this study. Preliminary analysis of the sloth bones recovered by the Indiana University project have shown the presence of what might be cut marks, although additional analysis is needed to confirm this (Riley and Maus 2014; Riley 2016, 2017). The appearance of humans on the Greater Antilles has been linked to faunal extinctions (Cooke et al. 2017). While there are some Taino artifacts that may have represented sloths (Veloz Maggiolo and Ortega 1976), the material found at Padre Nuestro would be the first direct evidence of human and sloth interactions in Hispaniola.

Inter-island Differences: While the amount of material presently available, both physical and published, of Parocnus browni is scarce, the differences between the Cuban (P. browni) and Hispaniolan (P. serus and $P$. dominicanus) forms revealed in this study deserve mention. Crania are historically important elements in paleontological descriptions, and both Hispaniola and Cuba lack such materials necessary for a detailed comparison between the species. The few differences between the Hispaniolan species and the descriptions put forth by Fischer (1971) suggest that even with sufficient comparative material that the inter-island cranial morphology of Parocnus would be fairly static.

The mandible exhibits more evolutionary plasticity with distinct characters separating the island species. For the two Hispaniolan species, the predental spout and the lingual trough along the symphysis are not parallel but expand labially around the caniniform. In contrast, the predental and symphyseal spout widths in $P$. browni are nearly uniform. The bowing in $P$. serus and $P$. dominicanus is attributed to the positioning and angle of the caniniform, which projects more laterally. The orientation of the lower caniniforms affects the ventral border of the dentary as the tooth root creates a distinct medial bulge into the lingual cavity just anterior to the enlargement for the molariforms. This feature is evident in both dorsal and ventral views, and it is not exhibited by P. browni. In dorsal view, there is also a greater mass of bone visible lateral to the crest of the diastema of both Hispaniolan species than in P. browni. The alveolus for the caniniform of the Hispaniolan species is more triangular in cross-section, whereas it is more curved and lunate in P. browni.

Inter-island differences are evident in the lateral development of the deltoid crest from the deltopectoral shelf, with the deltoid crest much less developed in P. browni. Imagining a plane passed from the greater tubercle to the lateral epicondyle, the deltoid crest of $P$. browni would be far removed from said plane. The lateral margin of the deltoid crest of $P$. serus would make full contact with such a plane and that of $P$. dominicanus would almost reach the same lateral extent. This more lateral placement of the $m$. deltoideus insertion (Toledo et al. 2013; Amson et al. 2015a) in both Hispaniolan species compared with the Cuban species indicates a more laterally positioned enthesis in the former and suggests distinctly different biomechanics of the front limb. The relative development of the pronator crest on the radius provides further evidence for differences in forelimb biomechanics between the Cuban and Hispaniolan Parocnus. The pronator crest in both $P$. serus and P. dominicanus is more 
developed than in P. browni, suggesting an increased ability to rotate the antebrachium and manus in the Hispaniolan species. Coupled with the differences in the humerus, it is possible that $P$. serus and $P$. dominicanus performed a wider array of forelimb motions and manipulations. It is certainly worth considering that there might have been differences in the habitats occupied by Parocnus in Cuba and Hispaniola and the role such differences may have played in the presence/absence of these morphological characters.

Although there is not enough material available to make similar inter-island comparisons of the hindlimb, there is one feature of the femur that may be significant. As noted in the description, both Hispaniolan species have a trochanteric fossa on the posterior surface of the greater trochanter while that feature is absent in the Cuban species. The trochanteric fossa is the attachment site for the small, inner pelvic muscles of $\mathrm{mm}$. gemelli and $\mathrm{m}$. obturatorius internus et externus, which generally aid in external rotation of the femur. The greater development and presence of a trochanteric fossa implies a greater use and strength of external hip rotation and extension for the Hispaniolan forms. It remains to be seen what other differences in the elements distal to the femur in order to better put into context the implications for this differential character.

\section{CONCLUSIONS}

Parocnus dominicanus is a new species of ground sloth from the southeastern region of the Dominican Republic that is smaller in size than Parocus serus. This new species also exhibits cranial and post-cranial characteristics that are distinct from those of the other Parocnus taxa: P. browni of Cuba and P. serus of Hispaniola. Remains come from two caves with the Nacional Parque del Este, one of which also has Taino archaeological artefacts, but $P$. dominicanus cannot be confirmed at this time to have been contemporaneous with the earliest occupants of Hispaniola.

Future areas of investigation include the examination of the link between habitat and morphology seen in Hispaniolan sloths. This would provide possible reasons for the morphological differences seen between species. Another significant addition would be the increased use of speleothem dating to gain somewhat better temporal control.

\section{ACKNOWLEDGEMENTS}

Authors are grateful to the initial fossil collection efforts of W. Pickle and C. Bowen, and the subsequent and continued work of the Dominican Republic Speleological Society. Additional thanks to the following institutions and staff for collections access and assistance: Museo del
Hombre Dominicano Museo Nacional de Historia Natural, Santo Domingo, University of Florida Museum of Natural History, Smithsonian Museum of Natural History.

\section{LITERATURE CITED}

Amson, E., C. Argot, H.G. McDonald, and C. de Muizon. 2015a. Osteology and functional morphology of the forelimb of the marine sloth Thalassocnus (Mammalia, Tardigrada). Journal of Mammalian Evolution 22:169-242.

Amson, E., C. Argot, H.G. McDonald, and C. de Muizon. 2015b. Osteology and functional morphology of the axial postcranium of the marine sloth Thalassocnus (Mammalia, Tardigrada) with paleobiological implications. Journal of Mammalian Evolution 22:473-518.

Anderson, R.P., and C.O. Handley Jr. 2001 A new species of three-toed sloth (Mammalia: Xenarthra) from Panamá, with a review of the genus Bradypus. Proceedings of the Biological Society of Washington 114:1-33.

Beeker, C.D., G.W. Conrad, and J.W. Foster. 2002. Taíno use of flooded caverns in the East National Park Region, Dominican Republic. Journal of Caribbean Archaeology 3:1-26.

Boscaini, A., D.A. Iurino, R. Sardella, G. Tirao, T.J. Gaudin, and F. Pujos. 2018. Digital cranial endocasts of the extinct sloth Glossotherium robustum (Xenarthra, Mylodontidae) from the late Pleistocene of Argentina: description and comparison with the extant sloths. Journal of Mammalian Evolution 27:55-71. doi:10.1007/s10914-018-9441-1.

Boscaini A., T.J. Gaudin, N. Toledo, B.M. Quispe, P. Antoine, and F. Pujos. 2019. The earliest well-documented occurrence of sexual dimorphism in extinct sloths: evolutionary and palaeoecological insights. Zoological Journal of the Linnean Society 187(1):229-239. doi:10.1093/zoolinnean/zlz011.

Brown, B. 1903. A new genus of ground sloth from the Pleistocene of Nebraska. Bulletin of the American Museum of Natural History 19:569-583.

Cartelle C., and G.A. Bohórquez. 1982. Eremotherium laurillardi Lund, 1842. Parte I. Determinaço especifica e dimorfismo sexual. Iheringia, Série Geológica 7:45-63.

Cartelle C., G. De Iuliis, A. Boscaini, and F. Pujos. 2019. Anatomy, possible sexual dimorphism, and phylogenetic affinities of a new mylodontine sloth from the late Pleistocene of intertropical Brazil. Journal of Systematic Palaeontology 17:1957-1988. doi:10.1080/14772019.2019.1574406.

Cartelle C., and G. De Iuliis. 2006. Eremotherium laurillardi (Lund) (Xenarthra, Megatheriidae), the panamerican giant ground sloth: taxonomic aspects of the ontogeny of skull and dentition. Journal of Systematic Palaeontology 4:199-209.

Delsuc, F., F.M. Catzeflis, M.J. Stanhope, and E.J.P. Douzery. 2001. The evolution of armadillos, anteaters and sloths depicted by nuclear and mitochondrial phylogenies: implications for the status of the enigmatic fossil Eurotamandua. Proceedings of the Royal Society of London B 268:1605-1615. 
Draper, G., P. Mann, and J.F. Lewis.1994. Hispaniola; pp. 129-155 in S.K. Donovan and T.A. Jackson (eds). Caribbean Geology: An Introduction. The University of the West Indies Publisher's Association (UWIPA), Kingston, Jamaica.

Fischer, K. 1971. Riesenfaultiere (Megalonychidae, Edentata, Mammalia) aus dem Pleistozoän der Pio-Domingo-Höhle in Kuba. Wissenschaftliche Zeitschrift der Humboldt-Universität zu Berlin, Mathematisch-Naturwissenschaftliche Reihe 20:609-673.

Flower, W.H. 1883. An Introduction to the Osteology of the Mammalia. Macmillan and Co., London, 382 pp.

Galliari, F.C., and A.A. Carlini. 2019. Xenarthran synsacrum morphology and evolution. Journal of Mammalian Evolution 26:493-504.

Gaudin, T.J. 1995. The ear region of edentates and the phylogeny of the Tardigrada (Mammalia, Xenarthra). Journal of Vertebrate Paleontology 15:672-705.

Gaudin, T.J. 1999. The morphology of xenarthrous vertebrae (Mammalia: Xenarthra). Fieldiana Geology, New Series 41:1-38.

Gaudin, T.J. 2004. Phylogenetic relationships among sloths (Mammalia, Xenarthra, Tardigrada): the craniodental evidence. Zoological Journal of the Linnean Society 140:255-305.

Gervais, F.L.P. 1855. Mammiféres. Animaux nouveaux ou rares recueillis pendant l'expédition dans les parties centrales de l'Amérique de sud. P. Bertrand, Paris, Volume I, 465 pp.

Hansford, J., J.M. Nuñez-Miño, R.P. Young, S. Brace, J.L. Brocca, and S.T. Turvey. 2012. Taxonomy-testing and the 'Goldilocks Hypothesis': morphometric analysis of species diversity in living and extinct Hispaniolan hutias. Systematics and Biodiversity 10:491-507.

Hautier L., V. Weisbecker, M.R. Sánchez-Villagra, A. Goswami, and R.J. Asher. 2010. Skeletal development in sloths and the evolution of mammalian vertebral patterning. Proceedings of the National Academy of Science USA 107:18903-8.

Kay, R.F., K.D. Hunt, C.D. Beeker, G.W. Conrad, C.C. Johnson, and J. Keller. 2011. Preliminary notes on a newly discovered skull of the extinct monkey Antillothrix from Hispaniola and the origin of the Greater Antillean Monkeys. Journal of Human Evolution 60:124-128.

Keller, J.A. 2009. Underwater archaeology of Padre Nuestro Cavern, Dominican Republic: sloth analysis. Undergraduate Thesis, Department of Underwater Archaeology, Indiana University, Indiana, USA. 63 pp.

Kurtén, B. 1953. On variation and population dynamics of fossil and recent mammal populations. Acta Zoologica Fennica 76:1-122.

Linneaus, C. 1758. Systema Naturae Perregna Tria Naturae, Secundum Classes, Ordines, Genera, Species Cum Characteribus, Differentiis, Syonymis, Locis. Laurentii Salvi, 824pp.

MacPhee, R.D.E., J.L. White, and C.A. Woods. 2000. New megalonychid sloths (Phyllophaga, Xenarthra) from the Quaternary of Hispaniola. American Museum Novitates 3303:1-32.

Matthew, W.D. 1931. Genera and new species of ground sloths from the Pleistocene of Cuba. American Museum Novitates 511:1-5.
Matthew, W.D. and C. de Paula Couto. 1959. The Cuban edentates. Bulletin of the American Museum of Natural History 117:1-56.

McAfee, R.K. 2016. Description of new postcranial elements of Mylodon darwinii Owen 1839 (Mammalia: Pilosa: Mylodontinae), and functional morphology of the forelimb. Ameghiniana 53:418-443.

McAfee, R.K., and S.M. Beery. 2017. Hispaniola-la! Underexplored intraspecific variation and taxonomy implications for island sloths (Mammalia: Pilosa: Megalonychidae). Journal of Vertebrate Paleontology 37(Program and Abstracts):160-161.

McAfee, R.K., and S.M. Beery. 2021. Intraspecific variation of megalonychid sloths from Hispaniola and the taxonomic implications. Historical Biology 33:371-386. doi.org/10.1080/0891 2963.2019.1618294

McAfee, R.K., and R.O. Rimoli. 2019. Easternmost occurrences of Neocnus (Mammalia, Pilosa, Megalonychidae) from the late Pleistocene-early Holocene of the Dominican Republic (Hispaniola). Journal of Vertebrate Paleontology. doi.org/10.10 80/02724634.2019.1624971

McDonald, H.G. 2006. Sexual dimorphism in the skull of Harlan's ground sloth. Contributions in Science, Natural History Museum of LA County 510:1-9.

Miller, G.S. 1922. Remains of mammals from caves in the Republic of Haiti. Smithsonian Miscellaneous Collection 74:1-8.

Miller, G.S. 1929. A second collection of mammals from caves near St. Michel, Haiti. Smithsonian Miscellaneous Collections 81:1-30.

Miño-Boilini, A.R., and A.E. Zurita. 2015. Dimorphism in quaternary scelidotheriinae (Mammalia, Xenarthra, Phyllogphaga). Palaeontologica Electronica 8.1.12A:1-16. doi:10.26879/434.

Naples, V.L. 1982. Cranial osteology and function in the tree sloths, Bradypus and Choloepus. American Museum Novitates 2739:1-41.

Naples, V.L. 1985. Form and function of the masticatory musculature in the tree sloths, Bradypus and Choloepus. Journal of Morphology 183:25-50.

Naples, V.L. 1989. The feeding mechanism in the Pleistocene ground sloth, Glossotherium. Contributions in Science, Natural History Museum of Los Angeles County 415:1-23.

Naples V.L., and R.K. McAfee. 2012. Reconstruction of the cranial musculature and masticatory function of the Pleistocene panamerican ground sloth Eremotherium laurillardi (Mammalia, Xenarthra, Megatheriidae). Historical Biology 24:187-206.

Naples V.L., and R. K. McAfee. 2014. Chewing through the Miocene: an examination of the feeding musculature in the ground sloth Hapalops from South America. F1000 Research 3:86. http://f1000research.com/articles/3-86/v1

Paula Couto, C de. 1956. On two mounted skeletons of Megalocnus rodens. Journal of Mammalogy 37:423-427.

Prothero, D., and K. Raymond. 2008. Variation and sexual dimorphism in Pleistocene ground sloths (Xenarthra). New Mexico Museum of Natural History and Science Bulletin 44:331-333. 
Riley, J. 2016. Possible evidence of sloth butchery: results from a faunal analysis of Padre Nuestro cavern, Dominican Republic. Abstracts of the SAA 81st Annual Meeting, p. 375.

Riley, J. 2017. Was the sloth the ultimate slow food? An archaeological examination of Padre Nuestro cavern, Dominican Republic. PhD Dissertation, Department of Anthropology, Indiana University, Bloomington, IN, USA. 350 pp.

Riley, J. and M. Maus. 2014. An exploration of marks on extinct sloth bones from a flooded cavern in the Dominican Republic. Abstracts of the SAA 79th Annual Meeting, pp. 634-635.

Rímoli, R. 1977. Una nueva especie de mono (Cebidae: Saimirinae: Saimiri) de La Hispaniola. Cuad. De CENDIA, Universiad Autonoma de Santo Domingo 242:5-14.

Rosenberger, A.L., S.B. Cooke, R. Rímoli, X. Ni, and L. Cardoso. 2011. First skull of Antillothrix bernensis, an extinct relict monkey from the Dominican Republic. Proceedings of the Royal Society B 278:67-74.

Rosenberger, A.L., Z.S. Klukkert, S.B. Cooke, and R. Rímoli. 2013. Rethinking Antillothrix: the mandible and its implications. American Journal of Primatology 75:825-836.

Rosenberger, A.L., R. Pickering, H. Green, S.B. Cooke, M. Tallman, A. Morrow, and R. Rímoli. 2015. 1.32+/- $0.11 \mathrm{Ma}$ age for underwater remains constrain antiquity and longevity of the Dominican primate Antillothrix bernensis. Journal of Human Evolution 88:85-96.

Scott, W.B. 1903-1904. Mammalia of the Santa Cruz beds. Reports of the Princeton University Expedition to Patagonia 5:1-490.

Simpson G.G., A. Roe, and R.C. Lewontin. 1960. Quantitative Zoology: numerical concepts and methods in the study of recent and fossil animals. McGraw Hill, New York, NY;

Taboada, G.S., W.S. Duque, and S.D. Franco S. 2007. Compendio de los Mamíferos Terrestres Autóctonos de Cuba: vivientes y extinguidos. Museo Nacional de Historia Natural, La Habana, Cuba. 465 pp.
Steadman, D.W., P.S. Martin, R.D.E. MacPhee, A.J. Tull, H.G. McDonald, C.A. Woods, M. Iturralde-Vinent, and G.W.L. Hodgins. 2005. Asynchronous extinction of late Quaternary sloths on continents and islands. Proceedings of the National Academy of Sciences 102:11763-11768.

Stock, C. 1925. Cenozoic gravigrade edentates of western North America with special reference to the Pleistocene Megalonychinae and Mylodontidae of Rancho La Brea. Carnegie Institute of Washington 331:1-206.

Taboada, G.S., W.S. Duque, and S.D. Franco S. 2007. Compendio de los Mamíferos Terrestres Autóctonos de Cuba: vivientes y extinguidos. Museo Nacional de Historia Natural, La Habana, Cuba. 466 pp.

Toledo, N., M.S. Bargo, and S.F. Vizcaíno. 2013. Muscular reconstruction and functional morphology of the forelimb of early Miocene sloths (Xenarthra, Folivora) of Patagonia. The Anatomical Record 296:305-325.

Veloz Maggiolo, M., and E. Ortega. 1976. The Preceramic of the Dominican Republic: some new finds and their possible relationships; pp. 147-201 in L.S. Robinson (ed). Proceedings of the First Puerto Rican Symposium on Archaeology. Fundación Arquelógia, Antropológica e Histórica de Puerto Rico, San Jan, Puerto Rico.

White, J.L., and R.D.E. MacPhee. 2001. The sloths of the West Indies: a systematic and phylogenetic review; pp. 201-235 in C.A. Woods and F E. Sergile (eds.). Biogeography of the West Indies: Patterns and Perspectives. CRC Press, Boca Raton, Florida.

Yablokov, A.V. 1974. Variability of Mammals. Published for the Smithsonian Institution and the National Science Foundation. Amerind Press, Washington, DC, 350 pp. 
Appendix 1. List of holotype and paratype specimens for Parocnus dominicanus.

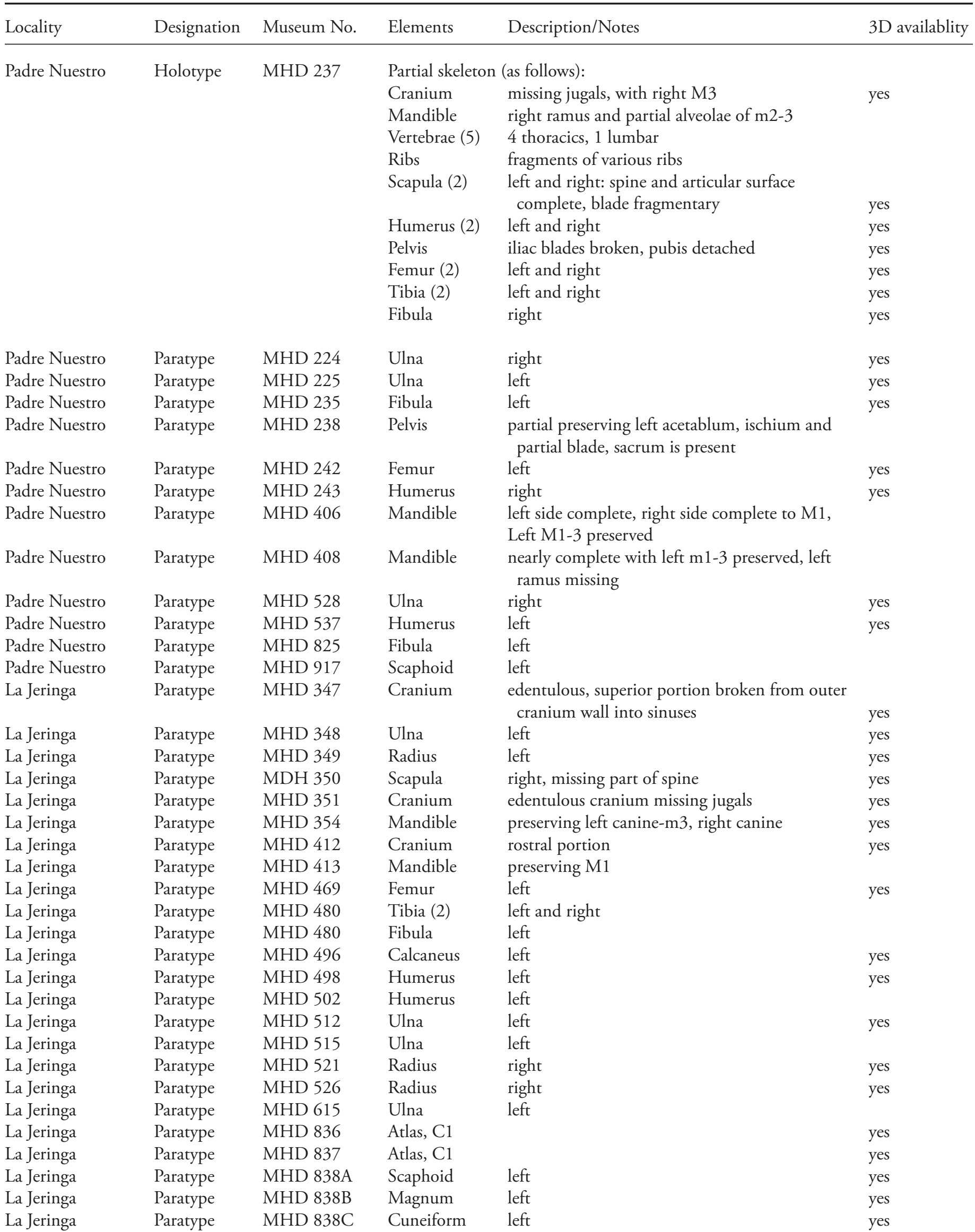


Vertebrate Anatomy Morphology Palaeontology 9:52-82

Appendix 1 continued. List of holotype and paratype specimens for Parocnus dominicanus.

Locality

Designation Museum No.

Elements

Description/Notes

3D availablity

La Jeringa

La Jeringa

Paratype

MHD 838D

MC III

left

yes

La Jeringa

Paratype

MHD 840

Scaphoid

right

right: same individual as MHD 912

yes

La Jeringa

MHD 841

MC III

Paratype MHD 909 Axis, C2

La Jeringa

Paratype

MHD 910

Axis, C3

Paratype

MHD 911

MC IV

MC IV

La Jeringa

MHD 912

Paratype

MHD 913

Paratype

MT II

La Jeringa

La Jeringa

Paratype

MHD 914

MT I

MHD 915

MT III

Paratype

MHD 916

MT IV

right

right: same individual as MHD 841

right

right

left

La Jeringa

left 